\title{
Simulation-Based and Risk-Informed Assessment of the Effectiveness of Tsunami Evacuation Routes Using Agent- Based Modeling: A Case Study of Seaside, Oregon
}

\author{
Zhenqiang Wang ${ }^{1} \cdot$ Gaofeng Jia $^{1}$
}

Accepted: 1 December 2021/Published online: 29 December 2021

(C) The Author(s) 2021

\begin{abstract}
Typically, tsunami evacuation routes are marked using signs in the transportation network and the evacuation map is made to educate people on how to follow the evacuation route. However, tsunami evacuation routes are usually identified without the support of evacuation simulation, and the route effectiveness in the reduction of evacuation risk is typically unknown quantitatively. This study proposes a simulation-based and risk-informed framework for quantitative evaluation of the effectiveness of evacuation routes in reducing evacuation risk. An agentbased model is used to simulate the tsunami evacuation, which is then used in a simulation-based risk assessment framework to evaluate the evacuation risk. The route effectiveness in reducing the evacuation risk is evaluated by investigating how the evacuation risk varies with the proportion of the evacuees that use the evacuation route. The impacts of critical risk factors such as evacuation mode (for example, on foot or by car) and population size and distribution on the route effectiveness are also investigated. The evacuation risks under different cases are efficiently calculated using the augmented sample-based approach. The proposed approach is applied to the riskinformed evaluation of the route effectiveness for tsunami evacuation in Seaside, Oregon. The evaluation results show that the route usage is overall effective in reducing the evacuation risk in the study area. The results can be used for evacuation preparedness education and hence effective evacuation.
\end{abstract}

Gaofeng Jia

Gaofeng.Jia@colostate.edu

1 Department of Civil and Environmental Engineering, Colorado State University, Fort Collins, CO 80523, USA
Keywords Agent-based model · Risk-informed evaluation $\cdot$ Route effectiveness $\cdot$ Simulation-based framework - Tsunami evacuation risk - Tsunami preparedness education

\section{Introduction}

The near-field earthquake-induced tsunami can result in substantial loss of life (Suppasri et al. 2012, 2013). Evacuation to safety zones (for example, shelters) is regarded as one of the most effective ways to survive a tsunami (Mas et al. 2012; Takabatake et al. 2017). Proper evacuation planning is crucial to support effective evacuation and reduce the evacuation risk (UNESCO 2007). To produce an effective evacuation plan for evacuation risk management, many issues need to be considered such as a good understanding of the evacuation behavior, an accurate evacuation risk assessment, and effective risk mitigation (Wang 2021). For effective risk mitigation, many strategies could be adopted (León and March 2016) such as extensive civilengineered defenses (for example, seawalls), land use, and built environment measures (for example, building codes), and emergency readiness systems (for example, evacuation preparedness). Tsunami preparedness education is believed to effectively raise people's awareness of tsunami risk, improve the evacuation, and ultimately reduce the casualty in tsunami-prone communities (Løvholt et al. 2019). For instance, the huge death tolls in the 2004 Indian Ocean tsunami were not seen in the 2011 Tohoku event, which can be partially attributed to the good preparedness of the population in some coastal communities in Tohoku (Løvholt et al. 2019). Preparedness education programs are held to increase people's awareness of the future tsunami (Adiyoso and Kanegae 2012; City of Rockaway Beach, 
Oregon 2019) and familiarity with facilities that are designed for evacuation (Adiyoso and Kanegae 2012). To raise people's tsunami awareness, community members (even the tourists) can be guided to visit tsunami museum, stranded vessel, and graveyard that are assigned as tsunami disaster educational facilities by the government (Adiyoso and Kanegae 2012). In addition, volunteer educators can go door-to-door to discuss tsunami awareness and safety with residents, hand out evacuation maps or brochures to residents (City of Rockaway Beach, Oregon 2019). To become familiar with evacuation facilities, people can visit the evacuation route and shelter building (Adiyoso and Kanegae 2012). People would easily find such facilities and evacuate to the shelter by following the evacuation route once a tsunami occurs.

Among various preparedness education programs, making tsunami hazard and evacuation maps is recommended to be the best way to start preparedness efforts (Dwelley Samant et al. 2008). Evacuation routes are marked in the evacuation map for the public to make their evacuation plans (that is, route selection) (Kurowski et al. 2011; DOGAMI 2013). In the evacuation, evacuees are encouraged to move to the nearest road and follow the route with evacuation signs to an assembly area, for example, horizontal or vertical shelter (Scheer et al. 2011; DOGAMI 2013). However, the evacuation route usage can be highly uncertain due to the variability in the characteristics of evacuees. Different types of evacuees (for example, residents and visitors) may have different knowledge, perception, or even experience on the evacuation route, which would impact the evacuation decision and behavior, especially the path selection (Limanond et al. 2011; Scheer et al. 2011; Takabatake et al. 2017). Typically, not all residents know their local evacuation routes (Dengler 2005), not to mention tourists. Learning about the evacuation map can make people (especially tourists) familiar with the evacuation route and effectively evacuate when the tsunami disaster strikes. Furthermore, some points need to be taken into account for the preparedness education about evacuation routes. Residents may have different views about the potential usefulness of evacuation routes (Dall'Osso and Dominey-Howes 2010). For example, some of the residents are concerned that evacuation routes will be blocked when many people follow the signs simultaneously (Bernard 2005). All of these can impact the evacuees' evacuation behavior (whether use the evacuation route or not, that is, there is uncertainty in the proportion of the evacuees that use the route), and ultimately impact the route effectiveness in reducing the evacuation risk in terms of casualty.

To gain high route effectiveness in reducing the evacuation risk through tsunami preparedness education (that is, educate people to effectively use the evacuation route), some important questions about the route effectiveness need to be answered. For example, does it always lead to a more effective evacuation by following the evacuation route compared to not following the route (for example, following the commonly used shortest path (Imamura et al. 2012; Yamamoto and $\mathrm{Li}$ 2017))? In what cases, is following the route more effective? Do the evacuation mode (for example, on foot or by car), population size, and population distribution have a high impact on the route effectiveness? If so, how do they impact the route effectiveness?

The answers to the above questions associated with the effectiveness of route usage may be found through understanding how the evacuation map is made, and evacuation routes are identified. Evacuation routes are marked in the evacuation map or brochure (in print or online) for the public to make the evacuation planning (that is, which route to follow in evacuation) (Kurowski et al. 2011; DOGAMI 2020a). Besides, web-based map interface by revising tsunami evacuation maps or interactive evacuation map viewer is available for the residents and visitors to custom design their own maps (DOGAMI 2020b). Evacuation maps for the at-risk communities along the coast are typically developed based on the state-developed inundation maps of a credible worst-case tsunami (Darienzo 2001; González et al. 2001; Priest et al. 2001; González et al. 2005; Tanioka et al. 2012). The inundation maps are produced through numerically efficient hydrodynamic model simulations with adequate, site-specific bathymetry and topography data (González et al. 2001, 2005). Evacuation routes are typically identified by local and state officials, and reviewed by the department that develops the inundation maps (González et al. 2001, 2005; Bernard 2005; Kurowski et al. 2011), or determined in close collaboration with communities and with feedback from tsunami experts (Bernard 2005). Some efforts exist in the search of highpriority tsunami evacuation routes for more effective evacuation (NTHMP 2018) or in the identification of the optimal evacuation route using various advanced algorithms, for example, the modified shortest path algorithm (Shekhar et al. 2012), the algorithm using GIS techniques (Schuster and Gomez 2013; Ai et al. 2016; Trindade et al. 2018), graph theory-based evacuation routing algorithm (Péroche et al. 2014; Patel et al. 2016), and discrete optimization algorithm (Forcael et al. 2014), and so on. However, to the best of our knowledge, the development of the tsunami evacuation map and identification of the evacuation route lack the support from evacuation simulation, and few efforts are put in the quantitative evaluation of the existing tsunami evacuation route effectiveness (that is, investigating the impact of route usage on the evacuation risk based on tsunami evacuation simulation). In this context, it is difficult or even impossible to implement an 
effective tsunami preparedness education on how to use the evacuation route effectively and hence improve the evacuation.

To address the above limitations, this study proposes a simulation-based and risk-informed approach to quantitatively evaluate the evacuation route effectiveness in reducing the evacuation risk for tsunami preparedness education. An agent-based model is used to simulate the tsunami evacuation, based on which the evacuation risk is quantified and assessed. The route effectiveness is evaluated by investigating how the evacuation risk varies with the proportion of the evacuees that use the evacuation route (that is, conditional evacuation risk assessment). The route effectiveness is also evaluated by investigating the impact of route usage on the evacuation risk under different values of critical risk factors (that is, the factors that have high impacts on the evacuation risk such as the proportion of the population that evacuate by car in the multi-modal evacuation, population size, and population distribution). The conditional evacuation risks are efficiently calculated using the augmented sample-based approach. The proposed approach is applied to the risk-informed evaluation of the route effectiveness for tsunami evacuation in Seaside, Oregon. However, the proposed approach is general and applicable to the evaluation of the route effectiveness in other regions with high tsunami risk around the world. Accordingly, the evaluation results can be used to improve the tsunami preparedness education (for example, guiding a more effective route usage) and hence the tsunami evacuation.

The remainder of this article is organized as follows. Section 2 describes the agent-based tsunami evacuation model for evacuation simulation. Section 3 presents the evaluation of route effectiveness through conditional evacuation risk assessment. Section 4 describes an illustrative example. Section 5 presents the results and discussions. Section 6 summarizes the research findings.

\section{Agent-Based Tsunami Evacuation Model}

For tsunami evacuation simulation, we use the agent-based evacuation model developed in Wang and Jia (2021a), which extends on the agent-based modeling (ABM) framework for a multi-modal near-field tsunami evacuation simulation proposed in Wang et al. (2016). The agentbased model used here is briefly reviewed.

The agent-based tsunami evacuation model (Fig. 1) consists of the evacuation environment model (EEM), evacuation decision and behavior model (EBM), and evacuation performance model (EPM). The EEM includes the multi-hazard model (that is, seismic and tsunami hazards), transportation network, tsunami shelter, and population distribution. Any seismic event that can trigger a tsunami and the resulting tsunami hazard can be incorporated into the multi-hazard model. The traffic capacity of the damaged link (that is, road/bridge) is reduced based on the seismic damage state predicted from fragility curves. The time histories of the tsunami inundation are generated using ComMIT/MOST (Titov and González 1997). Different population sizes and distributions throughout the community are modeled to characterize the population mobility. The population size (including the residents and tourists) is estimated considering the actual residential population and the population mobility. The population distribution can be of high spatiotemporal variability (Mostafizi et al. 2017). To model the uncertain population distribution throughout the community, different probability models such as the normal distribution and uniform distribution can be used (Mostafizi et al. 2017). In evacuation simulation, the population is limited to the hazard area. In the EBM, the evacuation decision and behavior are modeled. The evacuation decision includes the departure time, the multi-modal evacuation (that is, evacuation on foot and by car), and the path selection (for example, following the evacuation route or using the shortest path) throughout the transportation network. For the evacuation behavior, individual behavior, interactions between evacuees, and interactions between evacuees and the damaged environment are modeled. For individual evacuation behavior, the variability in the preferred pedestrian speed is modeled considering different characteristics of pedestrians. The speed is adjusted according to the corresponding traffic density ahead for both the pedestrian and car. The interactions between evacuees include those occurring between pedestrians or cars (for example, collision avoidance through speed adjustment), and between the pedestrian and car (for example, the pedestrian-vehicle interaction is modeled by traffic stage transition where the traffic stage is determined by the volume ratio of pedestrians to vehicles). In addition, evacuees would interact with the damaged environment. For example, the traffic capacity reduction of the damaged link would cause traffic congestion and hence slow down the evacuees' travel speed, which in turn impacts the traffic congestion level of the damaged link. The evacuees would need to reroute when some road is completely blocked or the bridge is completely damaged, which in turn impacts the traffic condition on the damaged transportation network. These dynamic interactions between evacuees and the damaged environment are also modeled. In the EPM, the quantity of interest such as the casualty rate (that is, the proportion of the number of casualties to the total population) is selected as the evacuation performance measure and the critical water depth is used to determine the casualty (that is, the 


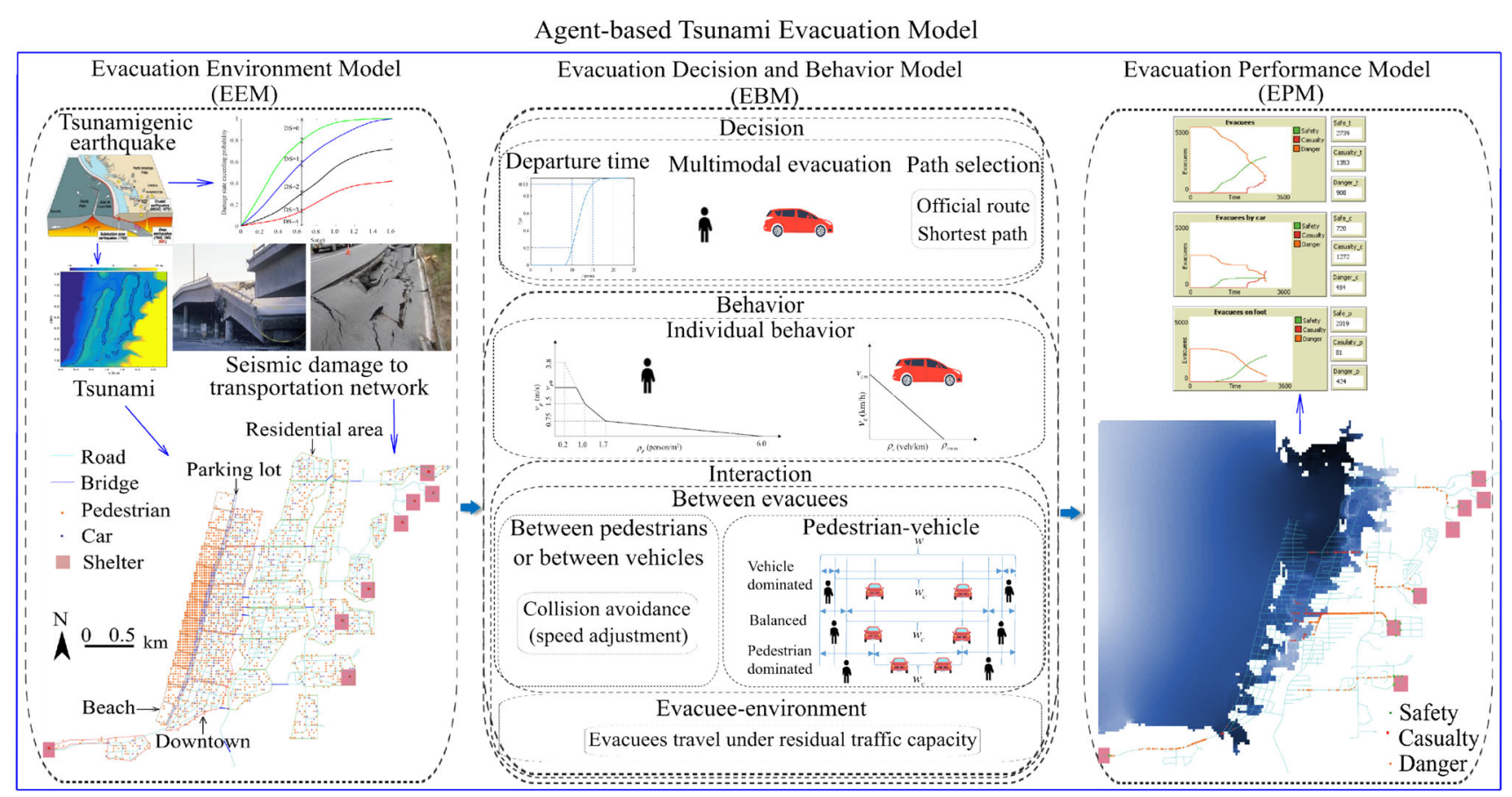

Fig. 1 Illustration of the agent-based tsunami evacuation model

evacuee is considered to become a casualty when the inundation depth exceeds the critical water depth).

The agent-based tsunami evacuation model is developed in NetLogo considering that the integrated ABM environment can use modern data with a high level of detail, capture the emergent phenomena, and tune the complexity of the agent's behavior (Wilensky 2001).

\section{Evaluation of Evacuation Route Effectiveness through Conditional Tsunami Evacuation Risk Assessment}

To evaluate the evacuation route effectiveness (that is, how the evacuation route usage impacts the evacuation risk), the evacuation risk under different proportions of the evacuees that use the evacuation route is evaluated. In addition, the impacts of critical risk factors such as evacuation mode (for example, on foot or by car) and population size and distribution on the route effectiveness are also investigated.

\subsection{Quantification of Tsunami Evacuation Risk}

To quantify the tsunami evacuation risk, the simulationbased framework in Wang and Jia (2021b) is used. Figure 2 shows a flowchart for the risk quantification. In the evacuation risk quantification, various uncertainties associated with the evacuation process (including the aleatory and epistemic uncertainty) are considered, such as those associated with the seismic damage to the transportation network in the EEM, the evacuation decisions and behaviors of evacuees (for example, departure time) in the EBM, and the critical water depth in the EPM. Let $\mathbf{x}=\left[\mathbf{x}_{e}, \mathbf{x}_{b}, \mathbf{x}_{p}\right]$ $=\left[x_{1}, \ldots, x_{i}, \ldots, x_{n x}\right] \in X$ represent all the input random variables in the space of $X$, where $\mathbf{x}_{e}, \mathbf{x}_{b}$, and $\mathbf{x}_{p}$ denote the input random variables in the EEM, EBM, and EPM, respectively, $x_{i}$ is the $i^{\text {th }}$ input random variable, and $n_{x}$ is the total number of input random variables. The probability model $p(\mathbf{x} \mid \boldsymbol{\theta})$ is used to quantify the uncertainty in $\mathbf{x}$, which corresponds to probability density function (PDF) for continuous variables or probability mass function (PMF) for discrete variables. Here $\boldsymbol{\theta} \in \boldsymbol{\Theta}$ represents the distribution parameters that define the probability model $p(\cdot \mid \boldsymbol{\theta})$, and $\boldsymbol{\Theta}$ is the space of all potential values of $\boldsymbol{\theta}$. When distribution parameters $\boldsymbol{\theta}$ are uncertain, the probability distribution $p(\boldsymbol{\theta})$ can be used to quantify the uncertainty in $\boldsymbol{\theta}$, which can be used to represent the epistemic uncertainty in the probability model for $\mathbf{x}$. Based on the evacuation simulation, the evacuation performance can be evaluated for any given realization of input $\mathbf{x}$. Let $h(\mathbf{x})$ represent the performance measure of the evacuation system for given $\mathbf{x}$. We can define $h(\mathbf{x})$ as the risk consequence measure. Depending on the quantity of interest, metrics such as the evacuation time needed to get a certain proportion of the population in the community to the safety zone, the number of people evacuated within a certain time frame, and the proportion of the number of casualties to the total population within a certain time frame (that is, casualty rate) 


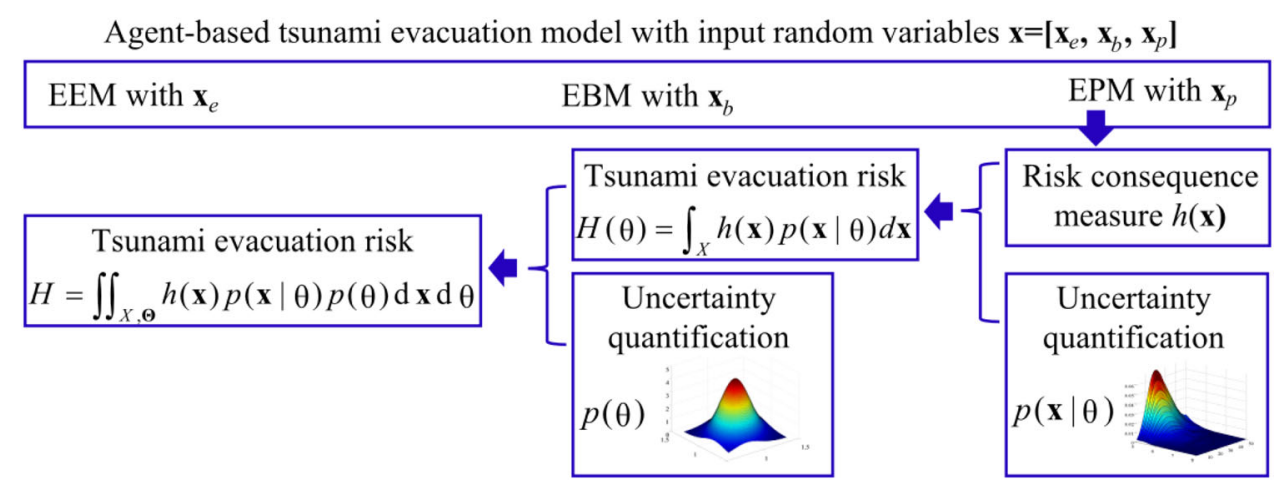

Fig. 2 Quantification of tsunami evacuation risk. EEM = evacuation environment model, EBM = evacuation decision and behavior model, $\mathrm{EPM}=$ evacuation performance model, $\mathbf{x}=$ all input random variables, $\mathbf{x}_{e}, \mathbf{x}_{b}, \mathbf{x}_{p}=$ input random variables in EEM, EBM, and EPM, respectively, $X=$ space of all potential values of $\mathbf{x}, h(\mathbf{x})=$ risk consequence measure, $\boldsymbol{\theta}=$ distribution parameters that define the

could be selected as the evacuation risk consequence measure. When $h(\mathbf{x})$ corresponds to the risk consequence measure (for example, the casualty rate), propagation of the uncertainties in $\mathbf{x}$ under given probability model $p(\mathbf{x} \mid \boldsymbol{\theta})$ leads to quantification of the evacuation risk (that is, conditional evacuation risk) $H(\boldsymbol{\theta})$

$H(\boldsymbol{\theta})=\int_{X} h(\mathbf{x}) p(\mathbf{x} \mid \boldsymbol{\theta}) d \mathbf{x}$

This corresponds to the evacuation risk under the given selection of distribution parameter $\boldsymbol{\theta}$. When $\boldsymbol{\theta}$ is uncertain, further propagating the uncertainties in $\boldsymbol{\theta}$ gives the evacuation risk $H$

$H=\iint_{X, \boldsymbol{\Theta}} h(\mathbf{x}) p(\mathbf{x} \mid \boldsymbol{\theta}) p(\boldsymbol{\theta}) \mathrm{d} \mathbf{x} \mathrm{d} \boldsymbol{\theta}$

\subsection{Conditional Tsunami Evacuation Risk}

To evaluate the effectiveness of route usage, an input variable $p_{r}$, which corresponds to the proportion of evacuees that use the evacuation route, is defined in $\mathbf{x}$ to characterize the amount of route usage. Probability model has been assigned to quantify the uncertainty in $p_{r}$. The evacuation risk $H$ already considered the uncertainty in $p_{r}$. Therefore, to evaluate the effectiveness of route usage, here the evacuation risk conditional on different $p_{r}$ values (that is, conditional on different proportion of evacuees that use the evacuation route) is used and investigated. This involves the evaluation of the conditional evacuation risk $H\left(p_{r}\right)$. Or more generally, the risk conditional on given value of scalar input random variable $x_{i}$, that is, $H\left(x_{i}\right)$, needs to be evaluated, and for $H\left(p_{r}\right)$ it simply corresponds to $H\left(x_{i}\right)$ for the case of $x_{i}$ being $p_{r}$. To evaluate $H\left(x_{i}\right)$, the uncertainties in $\mathbf{x}_{\sim i}$ and $\boldsymbol{\theta}$ need to be propagated, which leads to probability model $p(\cdot \mid \boldsymbol{\theta}), \boldsymbol{\Theta}=$ space of all potential values of $\boldsymbol{\theta}, p(\mathbf{x} \mid \boldsymbol{\theta})$ $=$ probability model that is used to quantify the uncertainty in $\mathbf{x}$ under given $\boldsymbol{\theta}, p(\boldsymbol{\theta})=$ probability distribution that is used to quantify the uncertainty in $\boldsymbol{\theta}, H(\boldsymbol{\theta})=$ tsunami evacuation risk under given $\boldsymbol{\theta}, H=$ tsunami evacuation risk

$H\left(x_{i}\right)=\iint_{X_{\sim i}, \boldsymbol{\Theta}} h\left(\mathbf{x}_{\sim i}, x_{i}\right) p\left(\mathbf{x}_{\sim i} \mid \boldsymbol{\theta}\right) p(\boldsymbol{\theta}) d \mathbf{x}_{\sim i} d \boldsymbol{\theta}$

where $\mathbf{x}_{\sim i}$ represents the remaining of the input random variables excluding $x_{i}$.

To gain more insights into the effectiveness of route usage, the impacts of critical risk factors such as evacuation mode (for example, on foot or by car) and population size on the route effectiveness are also investigated. This is realized by investigating the variation of the evacuation risk with $p_{r}$ under different values of the critical risk factors. Such investigation also involves the evaluation of the corresponding conditional evacuation risk, which can be written in general form as $H\left(\mathbf{x}_{i j}\right)$ with $\mathbf{x}_{i j}=\left[x_{i}, x_{j}\right]=\left[p_{r}, x_{j}\right]$ where $x_{j}$ represents one of the risk factors mentioned earlier. Similarly, to evaluate $H\left(\mathbf{x}_{i j}\right)$, the uncertainties in $\mathbf{x}_{\sim i j}$ and $\boldsymbol{\theta}$ need to be propagated, which leads to

$H\left(\mathbf{x}_{i j}\right)=\iint_{X_{\sim i j}, \boldsymbol{\Theta}} h\left(\mathbf{x}_{\sim i j}, \mathbf{x}_{i j}\right) p\left(\mathbf{x}_{\sim i j} \mid \boldsymbol{\theta}\right) p(\boldsymbol{\theta}) d \mathbf{x}_{\sim i j} d \boldsymbol{\theta}$

where $\mathbf{x}_{\sim i j}$ denotes the remaining of the input random variables excluding $\mathbf{x}_{i j}$.

The above conditional evacuation risks (that is, $H\left(x_{i}\right)$ and $\left.H\left(\mathbf{x}_{i j}\right)\right)$ correspond to high dimensional integral, and they can be approximated using stochastic simulation, for example, Monte Carlo simulation (MCS) (Robert and Casella 2004). However, direct application of MCS to estimate $H\left(x_{i}\right)$ requires large number of model evaluations and calculation of $H\left(x_{i}\right)$ for different values of $x_{i}$ would require repeating the above process and entails significant computational challenges, especially considering the fact that the evacuation model is expensive to run. Similar challenges hold for the evaluation of $H\left(\mathbf{x}_{i j}\right)$ for different $\mathbf{x}_{i j}$ values. 


\subsection{Efficient Calculation of Conditional Evacuation Risk Using the Augmented Sample-Based Approach and Kernel Density Estimation}

To efficiently estimate the above conditional evacuation risks, the augmented sample-based approach proposed in Wang (2021) is used, which extends on the sample-based approach introduced in Jia and Taflanidis (2016) for efficient estimation of Sobol' index. In the augmented approach, an augmented problem in terms of $[\mathbf{x}, \boldsymbol{\theta}]$ is first defined. Then, a joint auxiliary distribution $\pi(\mathbf{x}, \boldsymbol{\theta})$ with respect to $[\mathbf{x}, \boldsymbol{\theta}]$ is defined, which is proportional to the integrand of the evacuation risk integral $H$

$\pi(\mathbf{x}, \boldsymbol{\theta})=\frac{h(\mathbf{x}) p(\mathbf{x} \mid \boldsymbol{\theta}) p(\boldsymbol{\theta})}{H} \propto h(\mathbf{x}) p(\mathbf{x} \mid \boldsymbol{\theta}) p(\boldsymbol{\theta})$

based on which, the marginal auxiliary distribution for $x_{i}$ can be written as

$$
\begin{aligned}
\pi\left(x_{i}\right) & =\iint_{X_{\sim i}, \Theta} \pi(\mathbf{x}, \theta) d \mathbf{x}_{\sim i} d \theta \\
& =\frac{p\left(x_{i}\right) \iint_{X_{\sim i}, \Theta} h(\mathbf{x}) p\left(\mathbf{x}_{\sim i} \mid \theta\right) p(\theta) d \mathbf{x}_{\sim i} d \theta}{H}=\frac{p\left(x_{i}\right) H\left(x_{i}\right)}{H}
\end{aligned}
$$

Then $H\left(x_{i}\right)$ can be written as

$$
H\left(x_{i}\right)=\frac{\pi\left(x_{i}\right)}{p\left(x_{i}\right)} H
$$

Based on Eq. 7, $H\left(x_{i}\right)$ for any given value of $x_{i}$ can be efficiently estimated by: (1) generate a set of candidate samples $\left\{\left[\mathbf{x}^{k}, \boldsymbol{\theta}^{k}\right], k=1, \ldots, N\right\}$ from some joint proposal density $q(\mathbf{x}, \boldsymbol{\theta})$, and evaluate the corresponding $h(\mathbf{x}) ;(2)$ estimate the evacuation risk $H$ using

$\hat{H}=\frac{1}{N} \sum_{k=1}^{N} h\left(\mathbf{x}^{k}\right) \frac{p\left(\mathbf{x}^{k} \mid \boldsymbol{\theta}^{k}\right) p\left(\boldsymbol{\theta}^{k}\right)}{q\left(\mathbf{x}^{k}, \boldsymbol{\theta}^{k}\right)}$

The coefficient of variation $\left(\mathrm{CoV}\right.$, denoted $\left.\delta_{\mathrm{CoV}}\right)$ of the estimate can be also established; (3) pass these candidate samples through some stochastic sampling algorithm such as rejection sampling (Jia et al. 2017) to generate samples from the joint auxiliary PDF $\pi(\mathbf{x}, \boldsymbol{\theta})$, denoted $\left\{\left[\mathbf{x}_{\pi}^{k}, \boldsymbol{\theta}_{\pi}^{k}\right], k=1, \ldots, n_{\pi}\right\}$; (4) project the generated samples to the space of $x_{i}$, based on which an approximation to $\pi\left(x_{i}\right)$ (denoted as $\tilde{\pi}\left(x_{i}\right)$ ) is established using kernel density estimation (KDE) or the boundary corrected KDE for the input random variables that are bounded (Jia and Taflanidis 2016); (5) estimate the conditional evacuation risk under any value of $x_{i}$ efficiently using

$\hat{H}\left(x_{i}\right)=\frac{\tilde{\pi}\left(x_{i}\right)}{p\left(x_{i}\right)} \hat{H}$
Similarly, the conditional risk $H\left(\mathbf{x}_{i j}\right)$ can also be evaluated efficiently using the same set of $n_{\pi}$ samples. More specifically, projection of these samples to the $\mathbf{x}_{i j}$ space gives samples from the marginal density $\pi\left(\mathbf{x}_{i j}\right)$, and based on these marginal samples, an approximation to $\pi\left(\mathbf{x}_{i j}\right) \quad$ (denoted as $\tilde{\pi}\left(\mathbf{x}_{i j}\right)$ ) is established using the multivariate $\operatorname{KDE}$ (Jia and Taflanidis 2014, 2016). Then $\hat{H}\left(\mathbf{x}_{i j}\right)$ can be calculated under any given value of $\mathbf{x}_{i j}=\left[x_{i}\right.$, $x_{j}$ ] using

$\hat{H}\left(\mathbf{x}_{i j}\right)=\frac{\tilde{\pi}\left(\mathbf{x}_{i j}\right)}{p\left(\mathbf{x}_{i j}\right)} \hat{H}$

\section{Illustrative Example}

We perform the simulation-based and risk-informed evaluation of evacuation route effectiveness in Seaside, Oregon. The evacuation simulation corresponds to the case study in Wang and Jia (2021a); however, here two improvements are made to facilitate the investigation of route effectiveness. First, besides searching the shortest path in terms of distance, following the evacuation route is also considered an option for path selection in the evacuation model, and then the proportion of the evacuees who use the evacuation route is used to characterize the amount of route usage and quantify the route effectiveness. Second, instead of assuming the same cross-section for all links as in Wang and Jia (2021a), here the actual road cross-section is used for both the evacuation route and all other links in the transportation network. According to the road crosssection, roads with different widths are classified into different functional classifications (that is, "Principal Arterial," "Minor Arterial," "Major Collector," and "Local Road"), and maximum car speed limits are defined based on the different classifications. This improvement is made for a more realistic traffic simulation and hence for more accurate insights into the route effectiveness evaluation in the study area.

Next, the study area, Seaside, Oregon is described briefly. Then characteristics of the transportation network (especially those related to the road cross-section), tsunami evacuation route, and evacuation zone (especially those related to the evacuation route) are introduced in detail. Then implementation details for the evacuation simulation and the evacuation risk assessment are presented, including the case studies that are defined to investigate the route effectiveness.

\subsection{Study Area}

The coastal community of Seaside, Oregon (Fig. 3b), which has been selected in many tsunami evacuation 
(a) (b)

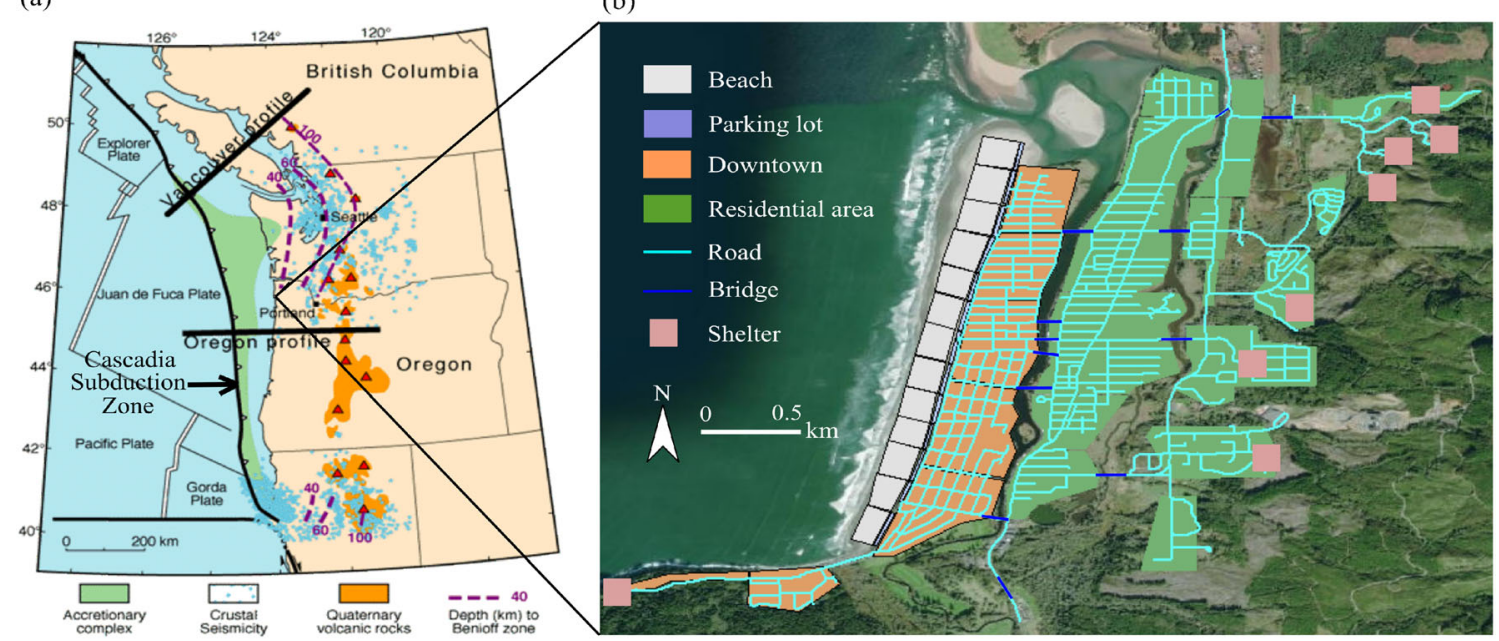

Fig. 3 The case study area. (a) Cascadia Subduction Zone (CSZ) (USGS 2020), and (b) Seaside, Oregon

related studies (Wang et al. 2016; Mostafizi et al. 2017, 2019), is selected as the study area. Seaside is regarded as one community with a high tsunami evacuation risk considering: (1) the high risk to the seismic and nearfield tsunami hazards due to the proximity to the Cascadia Subduction Zone (CSZ, shown in Fig. 3a) (Priest et al. 2016; Mostafizi et al. 2017); (2) the high vulnerability to tsunami inundation due to the fairly flat topography with two rivers flowing through the city, the relatively far shelters (more than $1.5 \mathrm{~km}$ ), and the bottlenecks in the transportation network caused by the 10 bridges over the two rivers (Mostafizi et al. 2017).

\subsection{Transportation Network}

Figure 4 shows the transportation network, which consists of 700 nodes and 896 links. The road cross-section standards corresponding to the federal functional classification of roads throughout Seaside (Clatsop County 2019) can be found in the typical design of streets in Clatsop County (City of Seaside 2010). Table 1 summarizes the values of the parameters used to determine the road width occupied by car and pedestrian (City of Seaside 2010). For a given functional class, $w$ represents the total road width (unit: $\mathrm{m}$ ); $w_{\text {wmin }}$ and $w_{w}$ represent the minimum and maximum road width (unit: $\mathrm{m}$ ) that can be used by the pedestrian; $w_{r}$ denotes the minimum width of each vehicle lane (unit: $\mathrm{m}$ ); $n_{l}$ represents the minimum number of vehicle lanes used. To model the pedestrian-vehicle interaction, different traffic stages are defined. More specifically, according to the volume ratio between pedestrians and vehicles, different traffic stages (that is, vehicle-dominated, balanced, and pedestrian-dominated) are dynamically selected to determine the road widths occupied by pedestrians and cars on the same link (Wang and Jia 2021a).
The well-known Greenshields' model of speed and density is used to simulate the car speed adjustment. Here the maximum car speed limit in the Greenshields' model is taken as $v_{c m}=64.4,56.3,48.3$, and 40.2 (unit: $\mathrm{kph}$ ) for Principal Arterial, Minor Arterial, Major Collector, and Local Road (ODOT 2020), respectively, and the traffic capacity of undamaged links is taken as $\rho_{c m}=200$ vehicle/ $\mathrm{km}$ based on the study in Mostafizi et al. (2017, 2019).

\subsection{Tsunami Evacuation Route and Evacuation Zone}

Following the approach in Lonergan et al. (2015), first the evacuation routes are identified using the evacuation map (DOGAMI 2013) and shapefiles (Claptsop County 2008). Note that one additional evacuation route that goes through the bridge over the river in downtown is added considering that the evacuees nearby would intuitively choose this route to go across the river (Hajo Neis et al. 2015). The identified evacuation routes are shown in Fig. 5.

Inspired by the evacuation map (DOGAMI 2013) and the beat-the-wave evacuation map for tsunami hazards in Seaside (Priest et al. 2016), the evacuation zone and evacuation direction are created throughout the community (Fig. 5) to determine the selection of the evacuation route by evacuees in each zone as well as the evacuation flow direction in the evacuation model. Note that in DOGAMI (2013) no evacuation zone is provided and therefore the evacuation direction is not designed for any specific evacuation zone. In Priest et al. (2016), both evacuation zone and the corresponding evacuation direction are created where the evacuation zones have complex shapes (determined from the least-cost distance calculation). In the current study, both the evacuation route and corresponding evacuation direction are established, but they are 
Fig. 4 The transportation network in Seaside, Oregon

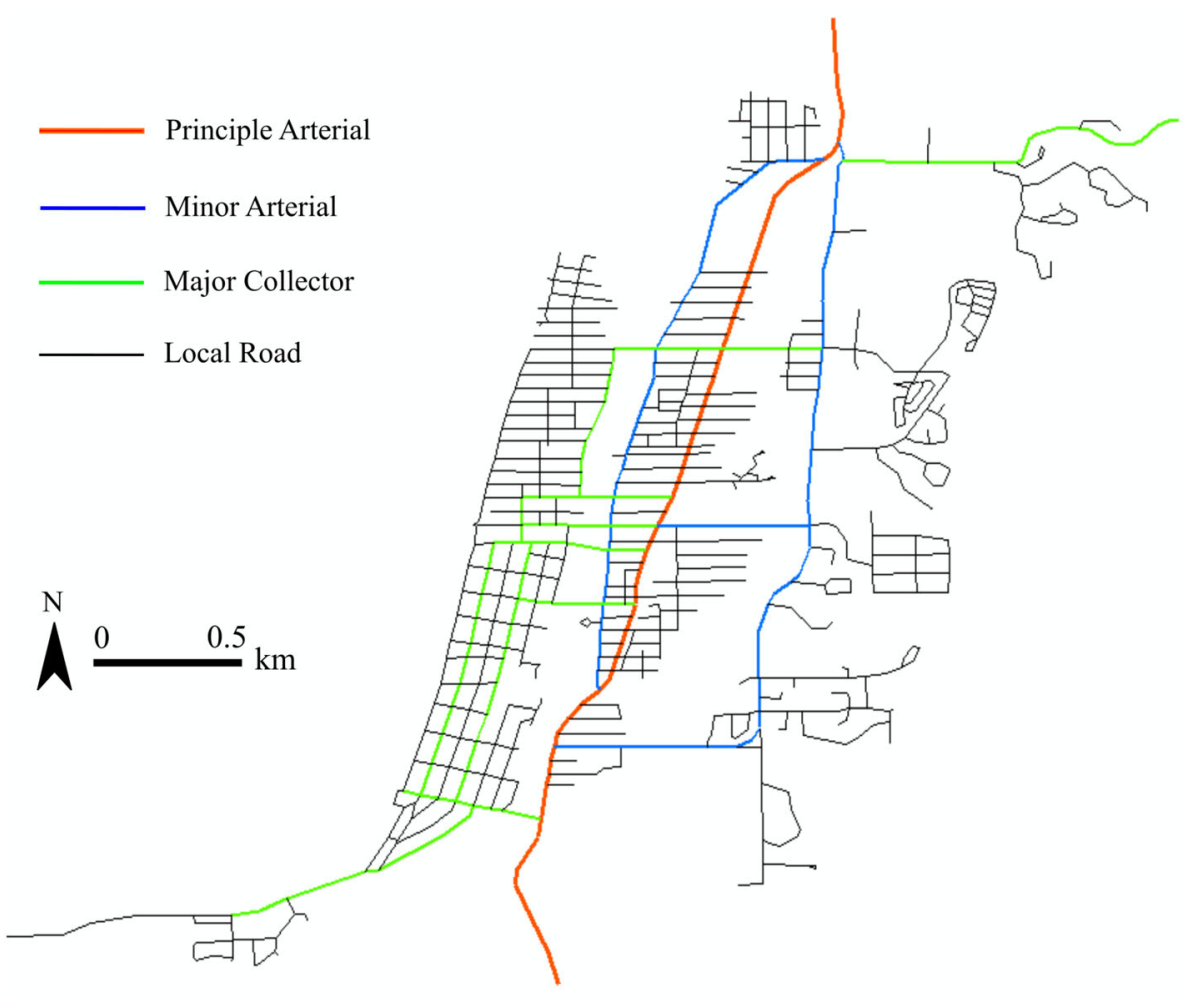

Table 1 The parameters used to determine the road width occupied by the car or pedestrian

\begin{tabular}{llllll}
\hline Functional class & $w$ & $w_{\text {wmin }}$ & $w_{w}$ & $w_{r}$ & $n_{l}$ \\
\hline $\begin{array}{l}\text { Principal } \\
\quad \text { Arterial }\end{array}$ & 12.80 & 4.49 & 5.49 & 2.75 & 2 \\
Minor Arterial & 10.97 & 2.66 & 3.66 & 2.75 & 2 \\
Major Collector & 10.36 & 2.66 & 3.66 & 2.75 & 2 \\
Local Road & 7.32 & 1.22 & 1.22 & 2.75 & 2 \\
\hline
\end{tabular}

$w=$ total road width, $w_{w \min }=$ the minimum road width that can be used by the pedestrian, $w_{w}=$ the maximum road width that can be used by the pedestrian, $w_{r}=$ the minimum width of each vehicle lane, $n_{l}=$ the minimum number of vehicle lanes used

established in a way that is different from DOGAMI (2013) and Priest et al. (2016). In particular, from the point of view of capturing the more possible selection and use of the evacuation route, the current study takes into account the following considerations about the creation of the evacuation zone and use of the evacuation route: (1) the region located between two main evacuation routes is divided into two evacuation zones such that the distance between each zone (centroid) and the adjacent route is close; (2) in each evacuation zone, the evacuees who decide to use evacuation routes will first move to the closest evacuation route and then follow the route to the shelter; (3) the evacuees who do not follow the evacuation route would search the shortest path; (4) when the bridge on some route collapses, the evacuees who plan to use the evacuation route would search the shortest path for evacuation.

\subsection{Implementation Details}

The historical seismic event in 1700 is selected as the hypothetical input of the multi-hazard scenario in which $M_{w}=9.0$ and the focal depth of $40 \mathrm{~km}$ are considered. This scenario corresponds to the maximum inundation area that is used in the evacuation map in Seaside, Oregon (Group 2006). We select the ground-motion prediction equations (GMPEs) in Campbell and Bozorgnia (2008) to estimate the permanent ground deformation (PGD) at each road site and spectral acceleration $\left(S_{a}\right)$ at each bridge site, respectively. Then the fragility functions of the road and bridge in HAZUS (DHS 2009) are used to estimate the probabilities for seismic damages to roads and bridges, respectively. According to the damage level (that is, none, slight, moderate, extensive, and complete), the residual traffic capacity of the road/bridge is calculated based on the residual rate of the traffic capacity defined in Wang and Jia (2021a). It is assumed that the evacuation occurs in summer and lasts for one hour after the occurrence of the earthquake. One hour is used because the tsunami would reach the run-up limit at around $55 \mathrm{~min}$ and the evacuation performance would become stable within one hour. 
Fig. 5 Tsunami evacuation routes and zones in Seaside, Oregon. The brown, pink, and green polygons represent the evacuation zones on the beach, in the downtown area, and in the residential area, respectively

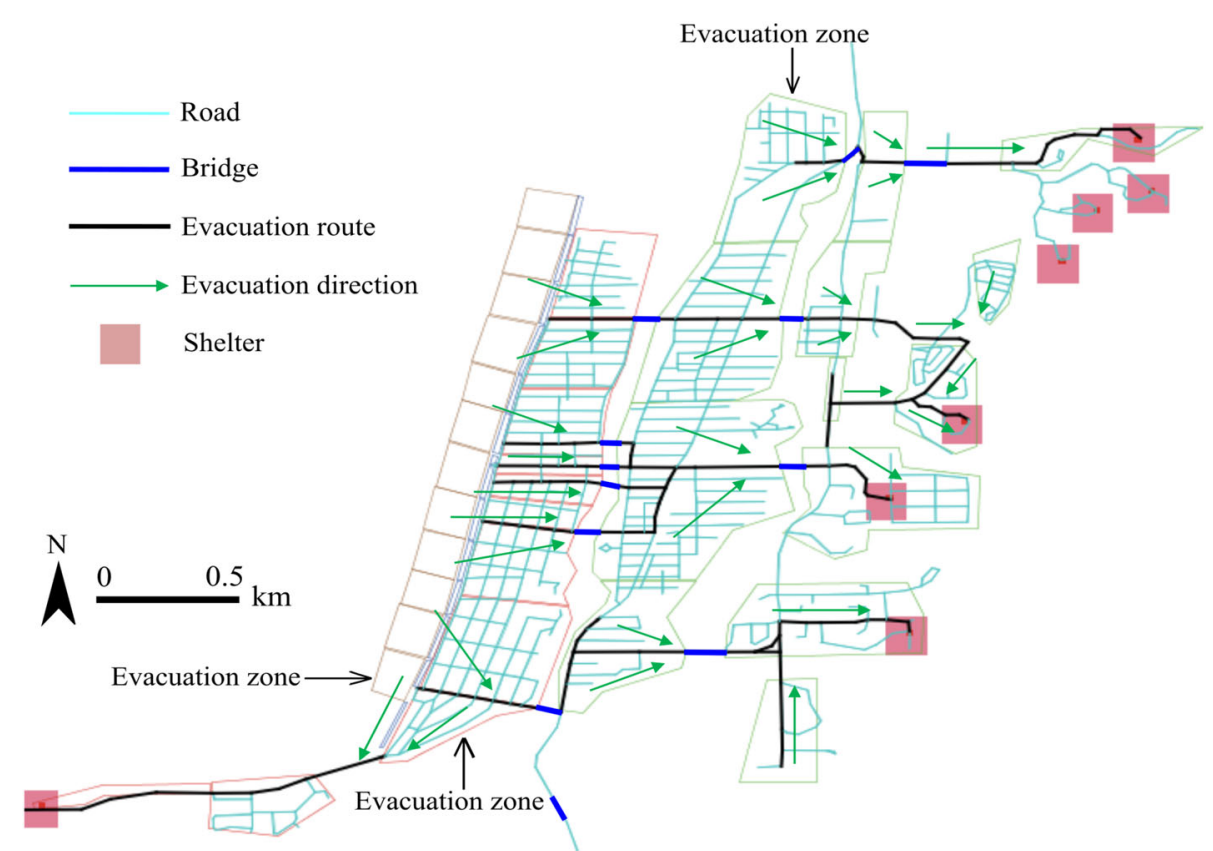

As for the input random variables, $\mathbf{x}_{e}=\left[\mathbf{x}_{d i}\right]$ with $i=1$, $2, \ldots, 896$ and $\mathbf{x}_{d i}$ corresponds to discrete random variable that represents the five seismic damage states of the links (that is, $\mathbf{x}_{d i}=D S_{j}$ with $j=1,2, \ldots, 5$ ). $\mathbf{x}_{b}=\left[t_{0}, t, p_{c}, T_{1 P}, T_{2 P}\right.$, $\left.T_{1 M}, T_{2 M}, T_{1 C}, T_{2 C}, T_{1 L}, T_{2 L}, v_{p}, p_{r}\right]$, and $\mathbf{x}_{p}=\left[h_{c}\right]$, where $t_{0}$ is the time when receiving the tsunami warning (unit: $\mathrm{min}$ ); $t$ is the departure time (unit: $\min$ ); $p_{c}$ denotes the proportion of the evacuees that use the car; $T_{1 P}, T_{2 P}, T_{1 M}, T_{2 M}, T_{1 C}$, $T_{2 C}, T_{1 L}$, and $T_{2 L}$ denote the thresholds that determine the traffic stage corresponding to the road class Principal Arterial, Minor Arterial, Major Collector, and Local Road, respectively; $v_{p}$ represents the pedestrian speed (unit: $\mathrm{m} / \mathrm{s}$ ); $p_{r}$ is the proportion of the evacuees that follow the evacuation route (the proportion of the evacuees that search the shortest path is $1-p_{r}$ ); $h_{c}$ represents the critical depth (unit: $\mathrm{m})$. The key continuous input random variables in $\mathbf{x}$ and corresponding distribution parameters in $\boldsymbol{\theta}$ are presented in Table 2, where $U$ and $T N$ represent the uniform distribution and truncated normal distribution, respectively. The selection of the probability distributions and values can be found in Wang (2021). For the $i$ th distribution parameter $\theta_{i}$, the subscripts "l" and " $u$ " represent the lower and upper bounds for the $i$ th input random variable $x_{i}$. For example, $l_{t 0}$ and $u_{t 0}$ are the lower and upper bounds for $t_{0}$, respectively. For other $\theta_{i}, \tau_{t}$ represents the delay time after receiving the tsunami warning and $\sigma_{t}$ is the scale parameter; $\mu_{c}$ and $\sigma_{c}$ denote the mean and standard deviation of $p_{c}$, respectively; $\mu_{p}$ and $\sigma_{p}$ are the mean and standard deviation of $v_{p}$, respectively. The values/distributions for the same $\theta_{i}$ are separated with semicolon (;), for example, for $\theta_{i}$ corresponding to $\tau_{t}$ and $\sigma_{t}, \tau_{t}$ follows $U[0,5]$ and $\sigma_{t}$ follows
$U[1,5]$, and they are separated with semicolon, written as $U[0,5] ; U[1,5]$.

In terms of the risk consequence measure $h(\mathbf{x})$, we use the casualty rate in the community within an hour. Here, we consider the pedestrian casualty rate (PCR), that is, that number of casualties that evacuate on foot divided by the total population, car casualty rate (CCR), that is, the number of casualties that evacuate by car divided by the total population, and total casualty rate (TCR), that is, the number of all casualties divided by the total population. Then, the evacuation risk corresponds to the expected PCR, CCR, and TCR, respectively.

It has been shown that some risk factors could have relatively high impacts on the tsunami evacuation risk, including the car use (that is, $p_{c}$ ) (Wang 2021; Wang and Jia 2021b), population size (Wang and Jia 2021a, 2021b) and distribution (Wang 2021). Here, the evacuation route effectiveness is evaluated under uncertain $p_{c}$ (that is, $H\left(p_{r}\right)$ ) and given values of $p_{c}$ (that is, $H\left(p_{r}, p_{c}\right)$ ), both of which are performed under different populations (denoted as $n_{e}$ ) and population distributions throughout the three sub-areas (denoted as $\rho_{1}, \rho_{2}$, and $\rho_{3}$ corresponding to the percentage of the population on the beach, in the downtown area, and in the residential area, respectively). Six cases (denoted as C1-C6) are defined in Table 3 to consider different population sizes and distributions. The up-to-date residential population of Seaside is 6795 in 2018 according to U.S. Census (U.S. Census Bureau 2018); however, the net daytime residential population can decrease to around half of the population (Sleeter and Wood 2006) while the number of tourists can be up to 10,000 per day in the peak 
Table 2 Key continuous input random variables and associated distribution parameters

\begin{tabular}{llll}
\hline$x_{i}$ & Distribution & $\theta_{i}$ & Value/distribution \\
\hline$t_{0}$ & $U$ & $l_{t 0} ; u_{t 0}$ & $3 ; 10$ \\
$t$ & Rayleigh & $\tau_{t} ; \sigma_{t}$ & $U[0,5] ; U[1,5]$ \\
$p_{c}$ & $T N$ & $\mu_{c} ; \sigma_{c} ; l_{p c} ; u_{p c}$ & $U[0,1] ; 0.15 ; 0 ; 1$ \\
$T_{1 P} ; T_{2 P}$ & $U$ & $l_{T 1 P} ; u_{T 1 P} ; l_{T 2 P} ; u_{T 2 P}$ & $1 ; 1.53 ; 2.3 ; 4.19$ \\
$T_{1 M} ; T_{2 M}$ & $U$ & $l_{T 1 M} ; u_{T 1 M} ; l_{T 2 M} ; u_{T 2 M}$ & $0.59 ; 0.97 ; 1.64 ; 3.14$ \\
$T_{1 C} ; T_{2 C}$ & $U$ & $l_{T 1 C} ; u_{T 1 C} ; l_{T 2 C} ; u_{T 2 C}$ & $0.59 ; 0.97 ; 1.53 ; 2.79$ \\
$T_{1 L} ; T_{2 L}$ & $U$ & $l_{T I L} ; u_{T I L} ; l_{T 2 L} ; u_{T 2 L}$ & $0.27 ; 0.38 ; 0.54 ; 1.04$ \\
$v_{p}$ & $T N$ & $\mu_{p} ; \sigma_{p}$ & $U[1.22,2.68] ; U[0.05,1]$ \\
& & $l_{v p} ; u_{v p}$ & $0.75 ; 3.83$ \\
$p_{r}$ & $U$ & $l_{p r} ; u_{p r}$ & $0 ; 1$ \\
$h_{c}$ & $U$ & $l_{h c} ; u_{h c}$ & $0.5 ; 2$ \\
\hline
\end{tabular}

$x_{i}=$ the $i$ th input random variable, $t_{0}=$ time when receiving the tsunami warning, $t=$ departure time, $p_{c}=$ proportion of the evacuees that use the car, $T_{1 P}, T_{2 P}, T_{1 M}, T_{2 M}, T_{1 C}, T_{2 C}, T_{1 L}$, and $T_{2 L}=$ thresholds that determine the traffic stage corresponding to the road class Principal Arterial, Minor Arterial, Major Collector, and Local Road, respectively, $v_{p}=$ pedestrian speed, $p_{r}=$ proportion of the evacuees that follow the evacuation route, $h_{c}=$ critical depth, $U=$ uniform distribution, $T N=$ truncated normal distribution, $\theta_{i}=$ the $i$ th distribution parameter, $\theta_{i}$ with subscripts " $l$ " and " $u$ " = lower and upper bounds for $x_{i}$, for example, $l_{t 0}$ and $u_{t 0}=$ lower and upper bounds for $t_{0}$, respectively, $\tau_{t}=$ delay time after receiving the tsunami warning, $\sigma_{t}=$ scale parameter, $\mu_{c}=$ mean of $p_{c}, \sigma_{c}=$ standard deviation of $p_{c}, \mu_{p}=$ mean of $v_{p}, \sigma_{p}=$ standard deviation of $v_{p}$

Table 3 Definition of evacuation simulation cases

\begin{tabular}{llll}
\hline & $n_{e}=5000$ & $n_{e}=10,000$ & $n_{e}=15,000$ \\
\hline Daytime cases & $\mathrm{C} 1$ & $\mathrm{C} 2$ & $\mathrm{C} 3$ \\
Nighttime cases & $\mathrm{C} 4$ & $\mathrm{C} 5$ & $\mathrm{C} 6$ \\
\hline
\end{tabular}

$n_{e}=$ population size

summer (Mostafizi et al. 2017), that is, population mobility exists. We select three population sizes (that is, $n_{e}=5000$, $n_{e}=10,000$, and $\left.n_{e}=15,000\right)$ to represent the population mobility. Here, $n_{e}=5000$ and $n_{e}=15,000$ are selected to represent the population size in the early summer and peak summer, respectively, while $n_{e}=10,000$ is used to model the population size during some time between the early summer and peak summer (Wang and Jia 2021a). Since the distribution varies with the time of the day, so two scenarios are defined to reflect this, corresponding to daytime and nighttime scenarios. Under the daytime scenario, the population is distributed across the three sub-areas with $\rho_{1}$ $=0.4, \rho_{2}=0.3$, and $\rho_{3}=0.3$ based on the study in Mostafizi et al. (2017). For the nighttime scenario, a larger proportion of evacuees would be in the downtown and the residential areas while fewer people would be on the beach. Here, $\rho_{1}=$ $0.1, \rho_{2}=0.5$, and $\rho_{3}=0.4$ are used. The population distributions and other related characteristics of the daytime and nighttime scenarios are summarized in Table 4. Note that all characteristics are applicable for the evacuations on foot and by car except "Preferred pedestrian speed." Due to the automotive lighting, the car speed is considered not to be affected during the night. Besides, the three speeds in the pedestrian speed-density model, that is, $0.75,1.5$, and 3.83 (unit: $\mathrm{m} / \mathrm{s}$ ) (Wang and Jia 2021a), are used here for the daytime scenario; to model the impact of nighttime (that is, worse lighting condition and shorter sight distance compared to daytime) on the pedestrian speed-density model, these three speeds are reduced by $20 \%$ for the nighttime scenario according to the study in Ouellette and Rea (1989), that is, reduced to 0.6, 1.2, and 3.06 (unit: $\mathrm{m} / \mathrm{s}$ ), respectively.

\section{Results and Discussions}

The augmented sample-based approach presented in Sect. 3.3 is used to efficiently estimate $H\left(p_{r}\right)$ and $H\left(p_{r}, p_{c}\right)$ under the six cases. For each case, we select $q(\mathbf{x}, \boldsymbol{\theta})=p(\mathbf{x} \mid \boldsymbol{\theta}) p(\boldsymbol{\theta})$ to generate $N=5,000$ candidate samples, based on which the corresponding $h(\mathbf{x})$ (that is, the PCR, CCR, and TCR) is evaluated. Under the selection of $q(\mathbf{x}, \boldsymbol{\theta})$ and $N=5,000$, all the $\delta_{C o V}$ for the estimate of $\hat{H}$ (that is, the expected PCR, CCR, and TCR) are below $2 \%$. For each case, using the information from the $N=5,000$ candidate samples, more than $n_{\pi}=300,1,500$, and 1,700 samples are generated from $\pi(\mathbf{x}, \boldsymbol{\theta})$ when $h(\mathbf{x})$ corresponds to the PCR, CCR, and TCR, respectively. Overall, for the cases with larger population size $n_{e}$, there are more samples from $\pi(\mathbf{x}, \boldsymbol{\theta})$ generated as a result of the relatively high evacuation risk. 
Table 4 Characteristics of daytime and nighttime scenarios

\begin{tabular}{lll}
\hline Characteristics & Daytime & Nighttime \\
\hline Lighting condition (lux) (Ahlström et al. 2018; Jacob et al. 2014) & 20,000 & 15 \\
Sight distance (m) (Aguilar et al. 2019) & 50 & 30 \\
Preferred pedestrian speed (m/s) (Ouellette and Rea 1989) & $v_{p 0}$ & $0.8 v_{p 0}$ \\
$\rho_{1}$ & 0.4 & 0.1 \\
$\rho_{2}$ & 0.3 & 0.5 \\
$\rho_{3}$ & 0.3 & 0.4 \\
\hline$\rho_{1} \rho_{2} \rho_{3}=p e r$
\end{tabular}

$\rho_{1}, \rho_{2}, \rho_{3}=$ percentage of the population on the beach, in the downtown area, and in the residential area, respectively, $v_{p 0}=$ preferred pedestrian speed

\subsection{Evaluation of Route Effectiveness under 5,000 Evacuees}

This section investigates the route effectiveness under 5,000 evacuees. In particular, the variations of the evacuation risk (that is, expected PCR, CCR, and TCR) with route usage and with both route usage and evacuation mode under the daytime and nighttime scenarios (that is, $\mathrm{C} 1$ and C4) are investigated.

\subsubsection{Variation of Evacuation Risk with Route Usage}

The variations of the expected casualty rates with the proportion of the evacuees that use the evacuation route (that is, $p_{r}$ ) for the PCR, CCR, and TCR under $\mathrm{C} 1$ and $\mathrm{C} 4$ are shown in Figs. $6 \mathrm{a}-\mathrm{c}$, respectively.

Daytime scenario $(\mathrm{Cl})$. As shown in Fig. 6a, the expected PCR almost does not change when $p_{r}$ is relatively small (that is, smaller than 0.35) while it decreases slightly as $p_{r}$ keeps increasing (that is, only decreases from $2.8 \%$ to $2.5 \%$ when $p_{r}$ increases from 0.35 to 1 ). This means if more pedestrians follow the evacuation route it will not reduce the PCR by much, hence for evacuation on foot following the evacuation route is not very effective in the risk reduction in this case. This low route effectiveness should be attributed to the close impacts of following the evacuation route and using the shortest path on the PCR under the relatively small population. Compared to following the evacuation route that is relatively wide and is distributed relatively evenly throughout the community, using the shortest path for pedestrians tends to induce a higher concentration of pedestrians on some links, especially when these links are relatively narrow (for example, Local Road). The higher concentration of pedestrians would cause more severe pedestrian congestion and hence more casualties due to the delay. This congestion is more obvious when the number of pedestrians is large. However, under $n_{e}=5,000$, the number of pedestrians is overall relatively small, and the pedestrian congestion level would not be much higher when using the shortest path. In other words, more pedestrians following the route (less pedestrians using the shortest path) would not help reduce the PCR by much under the relatively small population.

From Fig. 6b, the expected CCR first decreases slightly and then decreases significantly as $p_{r}$ increases, that is, from 21.2 to $20.7 \%$, and to $16.3 \%$ when $p_{r}$ increases from 0 to around 0.3 , and to 1 . Typically, evacuation by car tends to cause traffic congestion and hence casualties due to the delay caused by the congestion; this is true even under the relatively small population (that is, a small number of cars) (Mostafizi et al. 2019; Wang and Jia 2021a). The traffic congestion would become more severe on some links with the high concentration of cars when using the shortest path, especially on the links with significant traffic capacity reduction due to the bridge failure or road blockage. In this context, evacuation by car following the route would alleviate the traffic congestion on some links, and the alleviation would become significant as more cars drive on the evacuation route (for example, when $p_{r}$ is larger than $0.3)$. Then the overall evacuation by car would be improved a lot and the expected CCR would reduce significantly.

Due to the small variation of the PCR but the large variation of the CCR with $p_{r}$, the variation of the TCR (Fig. 6c) shows a similar trend to the CCR. The route effectiveness in reducing the evacuation risk (that is, the TCR) benefits from the route effectiveness for both evacuations on foot and by car, and further stems from the effectiveness in the congestion alleviation when using the relatively evenly distributed evacuation routes.

Nighttime scenario (C4) From Fig. 6a, the PCRs under any given value of $p_{r}$ as well as under the nighttime and daytime scenarios are very close, and hence the variations of the PCR with $p_{r}$ under the two scenarios are similar. Evacuation on foot is less likely to cause pedestrian congestion (Mostafizi et al. 2019), especially under a relatively 

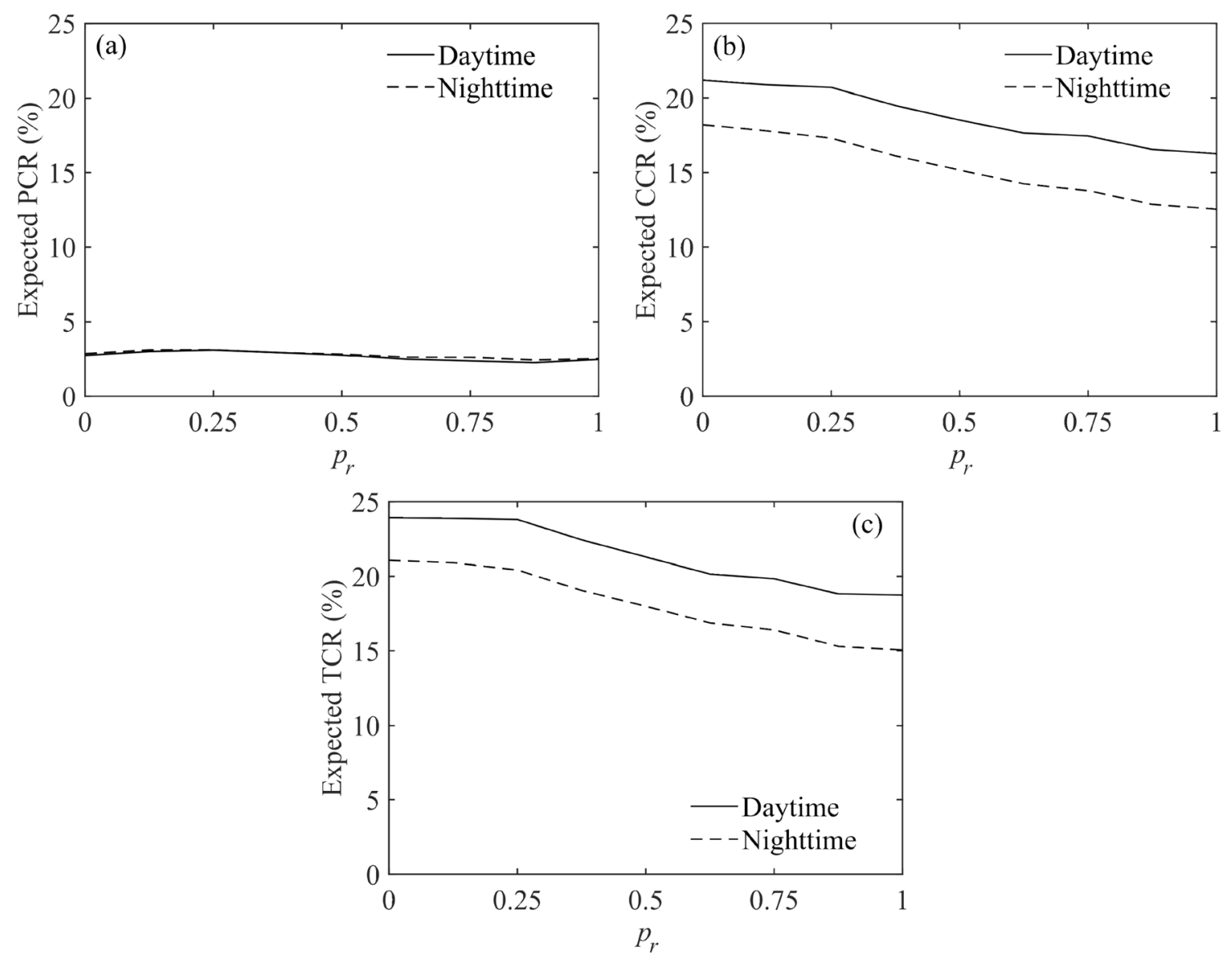

Fig. 6 Variation of expected casualty rate $H\left(p_{r}\right)$ as a function of proportion of evacuees that use the evacuation route $p_{r}$ for $(\mathbf{a})$ pedestrian casualty rate (PCR), (b) car casualty rate (CCR), and (c) total casualty rate (TCR) under cases $\mathrm{C} 1$ and $\mathrm{C} 4$

small number of pedestrians (Wang and Jia 2021a). In this case, the difference in the pedestrian speed or the population distribution across sub-areas between the daytime and nighttime scenarios would not change the pedestrian congestion level and the evacuation performance much (either when following the evacuation route or using the shortest path). Therefore, the PCRs are very close under any given value of $p_{r}$ and the two scenarios.

The variations of the CCR with $p_{r}$ under the daytime and nighttime scenarios (Fig. 6b) show a similar trend, although the CCR is lower for the nighttime scenario. Compared to the daytime scenario, the population distribution across sub-areas is overall closer to most of the shelters under the nighttime scenario. This would reduce the evacuation delay because of less traffic congestion (for example, only over a shorter evacuation distance) and hence reduce the CCR. However, as $p_{r}$ increases, the difference in the expected CCR between the daytime and nighttime scenarios does not seem to change much. Ultimately, the evacuation route usage has a similar impact on the reduction of the CCR under the two scenarios.
The variations of the TCR with $p_{r}$ under the daytime and nighttime scenarios (Fig. 6c) show a similar trend due to the similar variations of both the PCR and CCR with $p_{r}$ under the two scenarios. This indicates that following the evacuation route under different population distributions across sub-areas has similar effectiveness in reducing the evacuation risk (that is, the TCR) in this example.

In summary, as presented in Table 5, following the evacuation route can effectively reduce the evacuation risk under a relatively small population, especially for evacuation by car when a relatively large proportion of cars drive on the route in this example. This is true under different population distributions across sub-areas (that is, the daytime and nighttime scenarios). For tsunami evacuation planning, designation of evacuation routes has been applied in many areas of high tsunami risk such as the United States, Japan, and so on (Løvholt et al. 2019). However, even many residents may not know their official evacuation routes (Dengler 2005). Therefore, encouraging the public to learn about and follow the evacuation route is highly recommended in evacuation preparedness education. The education can be implemented by reading the evacuation 
Table 5 Major results under different simulation cases: Summary 1

\begin{tabular}{|c|c|c|}
\hline Cases & $H$ & Major results \\
\hline \multirow[t]{2}{*}{$\mathrm{C} 1$, } & $H\left(p_{r}\right)$ & $\begin{array}{l}\text { Following evacuation route is effective in the evacuation risk reduction (especially the CCR and TCR) under a relatively } \\
\text { small population and under different population distributions across sub-areas }\end{array}$ \\
\hline & $\begin{array}{r}H\left(p_{r},\right. \\
\left.p_{c}\right)\end{array}$ & $\begin{array}{l}\text { Reduction in the TCR due to following evacuation route is higher when more people evacuate by car; however, the TCR } \\
\text { increases significantly with the car use and the increase is much larger than the risk reduction }\end{array}$ \\
\hline C2, & $\begin{array}{r}H\left(p_{r}\right) \\
H\left(p_{r},\right. \\
\left.p_{c}\right)\end{array}$ & Similar to $\mathrm{C} 1, \mathrm{C} 4$ \\
\hline C3, 6 & $\begin{array}{r}H\left(p_{r}\right) \\
H\left(p_{r},\right. \\
\left.p_{c}\right)\end{array}$ & Similar to $\mathrm{C} 1, \mathrm{C} 4$ \\
\hline
\end{tabular}

$H=$ tsunami evacuation risk, $H\left(p_{r}\right)=$ tsunami evacuation risk under given proportion of the evacuees that use the evacuation route, $H\left(p_{r}, p_{c}\right)=$ tsunami evacuation risk under given proportion of the evacuees that use the evacuation route and evacuate by car

map (City of Rockaway Beach, Oregon 2019), recognizing the evacuation route (Adiyoso and Kanegae 2012), and so forth.

\subsubsection{Variation of Evacuation Risk with Route Usage and Evacuation Mode}

Figure 7 shows the variations of the expected casualty rates $H\left(p_{r}, p_{c}\right)$ as a function of $\left[p_{r}, p_{c}\right]$ under $\mathrm{C} 1$ and $\mathrm{C} 4$. Note that the view angle for Fig. $7 \mathrm{a}$ is different from those of Fig. 7c, e to facilitate better illustration. To make detailed observations, the variations of the expected casualty rates with $p_{r}$ under several selected values of $p_{c}$ (that is, $p_{c}=0$, $0.25,0.5,0.75$, and 1 ) are also shown.

Daytime scenario (C1). From Fig. 7a-e, the following observations can be made: (1) the PCR decreases as $p_{c}$ and $p_{r}$ increase, and more reductions are observed as $p_{c}$ varies; (2) the CCR increases as $p_{c}$ increases and decreases as $p_{r}$ increases, and much larger changes are found as $p_{c}$ varies; (3) compared to the PCR, overall the variation of the CCR as a function of $\left[p_{r}, p_{c}\right]$ is larger, especially the variation with $p_{c}$; (4) due to the above variations of the PCR and $\mathrm{CCR}$, the variation of the TCR as a function of $\left[p_{r}, p_{c}\right]$ shows a similar trend to that of the CCR.

Under any selected value of $p_{c}$ (except $p_{c}=1$, which corresponds to no evacuation on foot), overall the variation of the PCR with $p_{r}$ (Fig. 7b) is consistent with that under the uncertain $p_{c}$ (Fig. 6a). On the other hand, as $p_{r}$ increases, there is more reduction in PCR under the smaller value of $p_{c}$. For example, the reductions in PCR with the increase of $p_{r}$ (from 0 to 1 ) are around $2.0 \%$ and $0.3 \%$ when $p_{c}=0$ and $p_{c}=0.5$, respectively. This means the evacuation route effectiveness in the reduction of the PCR is higher when fewer people evacuate by car (that is, more people evacuate on foot). As discussed for the PCR under
C1 in Sect. 5.1.1, using the shortest path for pedestrians tends to cause a higher PCR than following the route. This difference in the PCR would become larger under a larger number of pedestrians due to more severe pedestrian congestion on some links using the shortest path. In this case, the reduction of the PCR by following the route would become larger when more people evacuate on foot.

Overall, the variation of the CCR with $p_{r}$ under any selected non-zero value of $p_{c}$ (Fig. $7 \mathrm{~d}$ ) is consistent with that under the uncertain $p_{c}$ (Fig. 6b). However, the reduction of the CCR is larger under the larger value of $p_{c}$, which indicates that the evacuation route usage has larger effectiveness in reducing the CCR when more people evacuate by car. This observation is similar to that for the PCR and can be explained similarly.

The variation of the TCR with $p_{r}$ under any selected value of $p_{c}$ (Fig. 7f) is similar to that under the uncertain $p_{c}$ (Fig. 6c). Furthermore, the route effectiveness in the reduction of the TCR is larger when more people evacuate by car while overall the TCR is also larger. More importantly, the reduction of the TCR by following the route is much smaller compared to the increase of the TCR as more people evacuate by car. For example, the largest reduction of the TCR is only $11.4 \%$ (that is, from $52.9 \%$ to $41.5 \%$ when $p_{r}$ increases from 0 to 1 ) at $p_{c}=1$ while the smallest increase of the TCR is $34.4 \%$ (that is, from $7.1 \%$ to $41.5 \%$ ) at $p_{r}=1$. To reduce the evacuation risk effectively, evacuation by car should be discouraged besides encouraging to follow the evacuation route in this example.

Nighttime scenario (C4). As shown in Fig. 7a, c, e, under the nighttime scenario, the variations of the expected casualty rates $H\left(p_{r}, p_{c}\right)$ as a function of $\left[p_{r}, p_{c}\right]$ demonstrate similarities to those under the daytime scenario, although the casualty rate under the same value of $\left[p_{r}, p_{c}\right]$ is overall lower. 

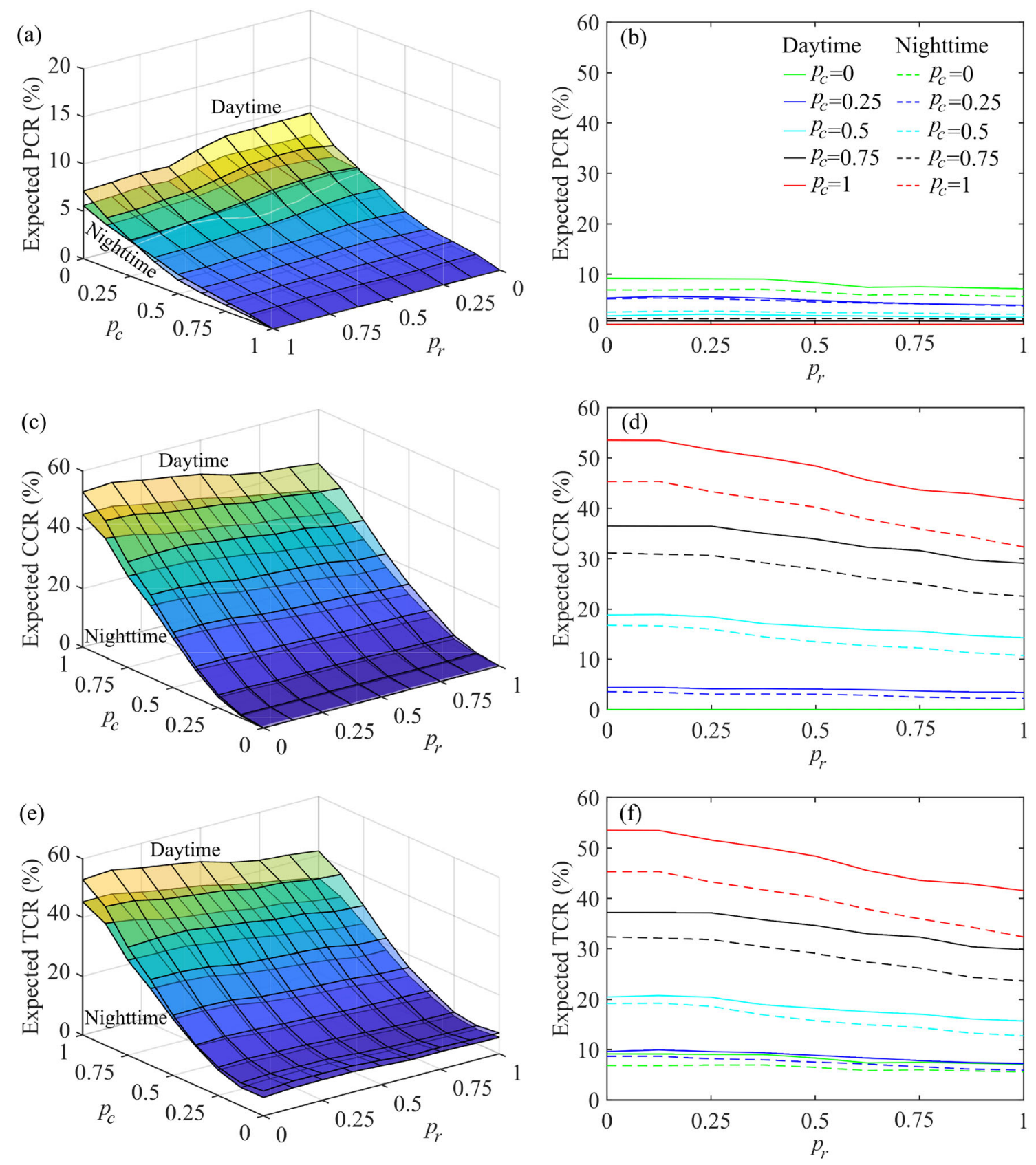

Fig. 7 Variation of expected casualty rate $H\left(p_{r}, p_{c}\right)$ as a function of proportion of evacuees that use the evacuation route and evacuate by car $\left[p_{r}, p_{c}\right]$ for (a) pedestrian casualty rate (PCR) under cases $\mathrm{C} 1$ and $\mathrm{C} 4$, (c) car casualty rate $(\mathrm{CCR})$ under $\mathrm{C} 1$ and $\mathrm{C} 4$, and (e) total

casualty rate (TCR) under $\mathrm{C} 1$ and $\mathrm{C} 4$, and variation of expected casualty rate $H\left(p_{r}\right)$ as a function of $p_{r}$ under several selected values of $p_{c}$ for (b) PCR under $\mathrm{C} 1$ and $\mathrm{C} 4$, (d) CCR under $\mathrm{C} 1$ and $\mathrm{C} 4$, and (f) TCR under $\mathrm{C} 1$ and $\mathrm{C} 4$

As for the variations of the expected casualty rates with $p_{r}$ under selected values of $p_{c}$ (Fig. $7 \mathrm{~b}, \mathrm{~d}, \mathrm{f}$ ), similar trends can also be found between the nighttime and daytime scenarios, although the PCRs under the two scenarios are relatively close while the CCR and TCR under the nighttime scenario are lower. For example, the reductions of the PCR (Fig. 7b) are, respectively, $2.0 \%$ and $1.3 \%$ at $p_{c}=0$ under the daytime scenario and nighttime scenario while

the corresponding reductions of the CCR (Fig. 7d) are $12.0 \%$ and $13.0 \%$ at $p_{c}=1$. This indicates that following the evacuation route has close effectiveness in the evacuation risk reduction under the daytime and nighttime scenarios.

Based on the above results under the daytime and nighttime scenarios (summarized in Table 5), the evacuation route usage is effective in reducing the evacuation risk. 

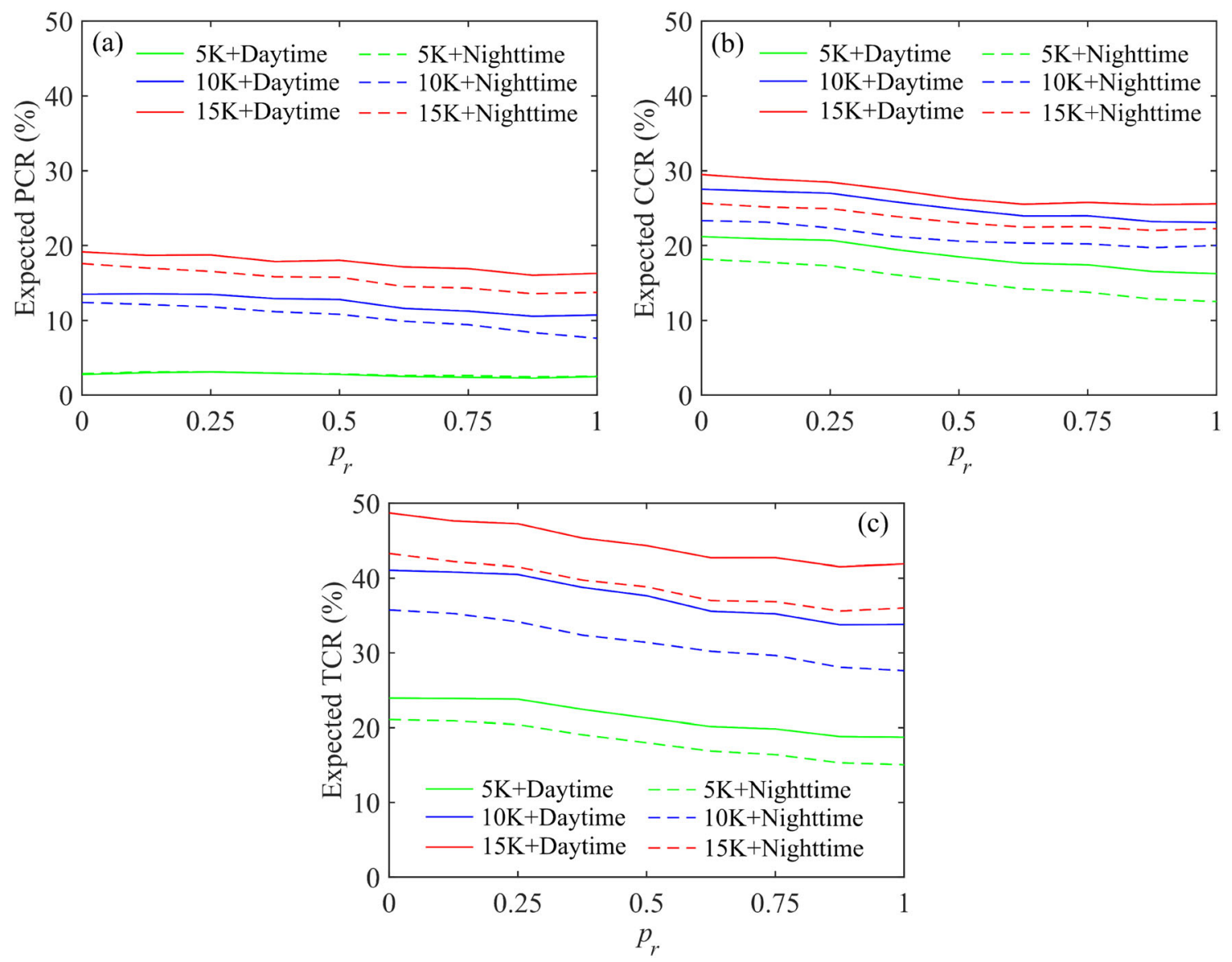

Fig. 8 Variation of expected casualty rate $H\left(p_{r}\right)$ as a function of proportion of evacuees that use the evacuation route $p_{r}$ for (a) pedestrian casualty rate $(\mathrm{PCR}),(\mathbf{b})$ car casualty rate $(\mathrm{CCR})$, and $(\mathbf{c})$ total casualty rate $(\mathrm{TCR})$ under cases $\mathrm{C} 1-\mathrm{C} 6$

When more people evacuate by car, the reduction in the evacuation risk is higher as more people follow the evacuation routes. These hold under different population distributions across sub-areas (that is, the daytime and nighttime scenarios). However, the TCR increases significantly with car use and the increase is much larger than the risk reduction resulting from following the evacuation route. Existing research has shown that evacuation by car is more likely to cause a larger evacuation risk (Mostafizi et al. 2019; Wang and Jia 2021a). Also, significant casualties due to the evacuation delay caused by a large amount of car use have occurred in historical tsunami evacuations (Murakami et al. 2014). Therefore, for more effective tsunami evacuation risk reduction, following the evacuation route is encouraged and evacuation on foot instead of by car is recommended in this example. However, typically people would prefer to evacuate by car (Murakami et al. 2014). Therefore, to address such issues, strategic planning can be carried out, for example, designing a tsunami evacuation drill to discourage people from evacuating by car through experiencing the evacuation delay caused by traffic congestion (Wang 2021).

\subsection{Evaluation of Route Effectiveness under Different Population Sizes}

This section investigates the route effectiveness under different population sizes. For each population size, the variations of the evacuation risk (that is, expected PCR, CCR, and TCR) with route usage and with both route usage and evacuation mode under the daytime and nighttime scenarios (C1-C6) are investigated.

\subsubsection{Variation of Evacuation Risk with Route Usage}

The variations of the expected casualty rates with the proportion of the evacuees that use the evacuation route (that is, $p_{r}$ ) for PCR, CCR, and TCR under C1-C6 are shown in Fig. 8a-c, respectively.

Daytime scenario $(C 1-C 3)$ The variations of the PCR with $p_{r}$ under $n_{e}=10,000$ and $n_{e}=15,000$ show some similarities to that under $n_{e}=5,000$ (Fig. 8a), for example, the PCR would reduce as more pedestrians evacuate through following the evacuation route. However, the reduction of 
the PCR when $p_{r}$ increases from 0 to 1 is larger under the relatively large population, that is, $0.3 \%, 2.8 \%$, and $2.9 \%$ under $n_{e}=5,000,10,000$, and 15,000, respectively. Unlike under the relatively small population (that is, $n_{e}=5,000$ in Sect. 5.1.1), the pedestrian congestion level on some links would be much higher when using the shortest path than following the route under the relatively large population (that is, $n_{e}=10,000, n_{e}=15,000$ ). In this case, the route usage would be more effective in the alleviation of pedestrian congestion and hence in the reduction of casualties. Note that the route effectiveness does not increase much (that is, from $2.8 \%$ to $2.9 \%$ ) as the population increases from 10,000 to 15,000 . This is because under the relatively large population, following the evacuation route for pedestrians tends to induce pedestrian congestion as severe as using the shortest path. In this context, following the route would not reduce the evacuation delay and casualty rate for pedestrians much more than using the shortest path.

By comparing the variations of the CCR with $p_{r}$ under different populations shown in Fig. 8b, some similarities can be found such as the CCR decreases as $p_{r}$ increases. However, overall the reduction of the CCR when $p_{r}$ increases from 0 to 1 becomes smaller (though not by much) under the relatively large population, that is, $4.9 \%$, $4.5 \%$, and $3.9 \%$ under $n_{e}=5,000, n_{e}=10,000$, and $n_{e}=$ 15,000 , respectively. This is because under a larger population, following the evacuation route for cars would also cause more severe traffic congestion as using the shortest path, which makes the alleviation of the traffic congestion by following the route smaller.

In comparison to the case for $n_{e}=5,000$, the variations of the TCR with $p_{r}$ under $n_{e}=10,000$, and $n_{e}=15,000$ (Fig. 8c) demonstrate some similar trends, for example, overall the TCR decreases with the increase of $p_{r}$. As $p_{r}$ increases from 0 to 1 , however, overall the reduction of the TCR is large under the relatively large population, that is, $5.2 \%, 7.3 \%$, and $6.8 \%$ under $n_{e}=5,000, n_{e}=10,000$, and $n_{e}$
$=15,000$, respectively. This indicates the route effectiveness in the reduction of the TCR is overall higher under the relatively large population. In addition, the reduction in the TCR is smaller under the relatively large value of $p_{r}$ (for example, when $p_{r}$ is larger than 0.9 ) and relatively large population. This indicates that the route effectiveness in the reduction of the TCR would decrease when most of the evacuees follow the route, especially under the relatively large population.

Nighttime scenario (C4-C6) From Fig. 8a-c, under the same population, overall the variations of the PCR, CCR, and TCR with $p_{r}$ under the nighttime scenario are not very different from that under the daytime scenario, although the evacuation risk is overall lower under the nighttime scenario. In this context, the impact of the population size on the variations of the PCR, CCR, and TCR with $p_{r}$ demonstrates similar trends between the daytime and nighttime scenarios, for example, the route effectiveness in the reduction of the TCR is overall higher under the relatively large population (the reductions of the TCR under the nighttime scenario are $6.0 \%, 8.1 \%$, and $7.3 \%$ under $n_{e}$ $=5,000, n_{e}=10,000$, and $n_{e}=15,000$, respectively).

To summarize based on the above results (Tables 5 and 6), overall the evacuation route usage can also effectively reduce the evacuation risk under the relatively large population with different distributions across sub-areas, either for the pedestrian, car, or total in this example. For better evacuation preparedness education and hence for the improvement of evacuation, it is recommended to encourage the public to follow the evacuation route when the tsunami strikes.

\subsubsection{Variation of Evacuation Risk with Route Usage and Evacuation Mode}

Figure 9 shows the variations of the expected casualty rates $H\left(p_{r}, p_{c}\right)$ as a function of $\left[p_{r}, p_{c}\right]$ under $\mathrm{C} 1-\mathrm{C} 6$. Note that

Table 6 Major results under different simulation cases: Summary 2

\begin{tabular}{lrl}
\hline Cases & $H$ & Major results \\
\hline C1, C2, & $H\left(p_{r}\right)$ & $\begin{array}{r}\text { Following evacuation route is effective in the evacuation risk reduction under different population sizes and the } \\
\text { effectiveness in the reduction of the TCR is overall higher under the relatively large population }\end{array}$ \\
& $\begin{array}{r}H\left(p_{r},\right. \\
\left.p_{c}\right)\end{array}$ & $\begin{array}{r}\text { Route effectiveness in the reduction of the TCR is larger when more people evacuate by car while overall the TCR is also } \\
\text { larger; the effectiveness does not keep increasing with the car use and also does not change much under the relatively } \\
\text { large population }\end{array}$ \\
C4, C5, & $\begin{aligned} H\left(p_{r}\right) \\
\text { C6 }\end{aligned}$ & $\begin{aligned} H\left(p_{r},\right. \\
\left.p_{c}\right)\end{aligned}$
\end{tabular}

$H=$ tsunami evacuation risk, $H\left(p_{r}\right)=$ tsunami evacuation risk under given proportion of the evacuees that use the evacuation route, $H\left(p_{r}, p_{c}\right)=$ tsunami evacuation risk under given proportion of the evacuees that use the evacuation route and evacuate by car 

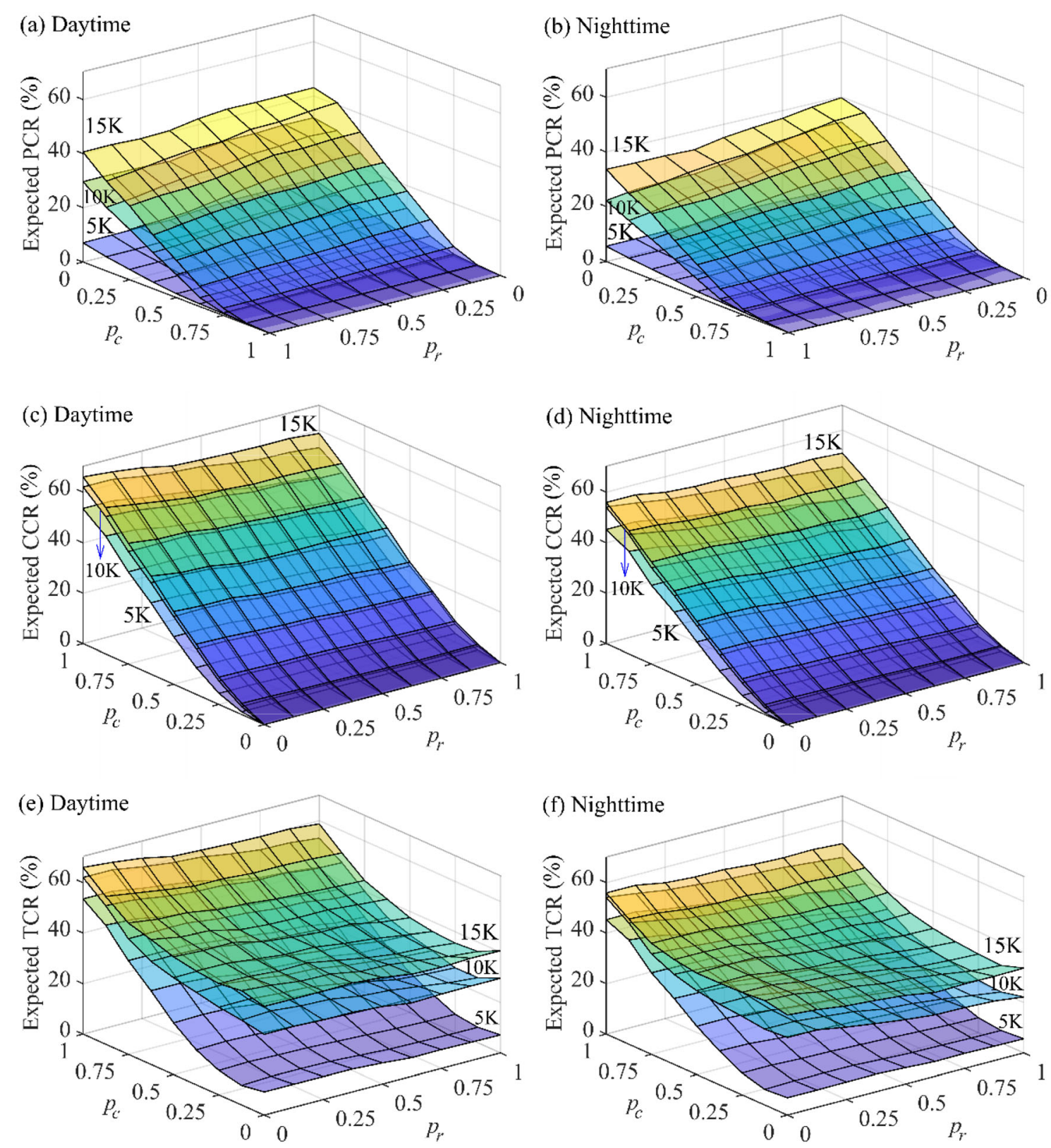

Fig. 9 Variation of expected casualty rate $H\left(p_{r}, p_{c}\right)$ as a function of proportion of evacuees that use the evacuation route and evacuate by car $\left[p_{r}, p_{c}\right]$ for $(\mathbf{a})$ pedestrian casualty rate $(\mathrm{PCR})$ under cases $\mathrm{C} 1-\mathrm{C} 3$,

the view angles for Fig. 9a, b are different from those of Fig. 9c-f to facilitate better illustration. To make more detailed observations, the variations of the expected casualty rates with $p_{r}$ under several selected values of $p_{c}$ (that is, $p_{c}=0,0.25,0.5,0.75$, and 1) are shown in Fig. 10.

Daytime scenario (C1-C3) As shown in Fig. 9a, c, e, under the daytime scenario, the variations of the expected casualty rate as a function of $\left[p_{r}, p_{c}\right]$ under $n_{e}=10,000$ and $n_{e}=$ 15,000 demonstrate similar trends to that under $n_{e}=5000$ for PCR, CCR, and TCR. However, under any given value

(b) PCR under C4-C6, (c) car casualty rate (CCR) under $\mathrm{C} 1-\mathrm{C} 3$, (d) CCR under $\mathrm{C} 4-\mathrm{C} 6$, (e) total casualty rate (TCR) under $\mathrm{C} 1-\mathrm{C} 3$, and (f) TCR under C4-C6

of $p_{r}$, as $p_{c}$ increases, overall the reduction in the PCR or the increase in the CCR is larger while the increase in the TCR is smaller under the larger population.

Under the relatively large population (that is, $n_{e}=10,000$ or $\left.n_{e}=15,000\right)$, the variations of the PCR with $p_{r}$ under different given values of $p_{c}$ show similarities to those under $n_{e}=5000$ (Fig. 10a) and can be explained similarly as discussed in Sect. 5.1.2. Around medium values of $p_{c}$ (that is, not too small or too large values of $p_{c}$ ), however, the variation of the PCR with $p_{r}$ under the relatively large population is different from that under $n_{e}=5000$. For example, when $p_{c}=$ 

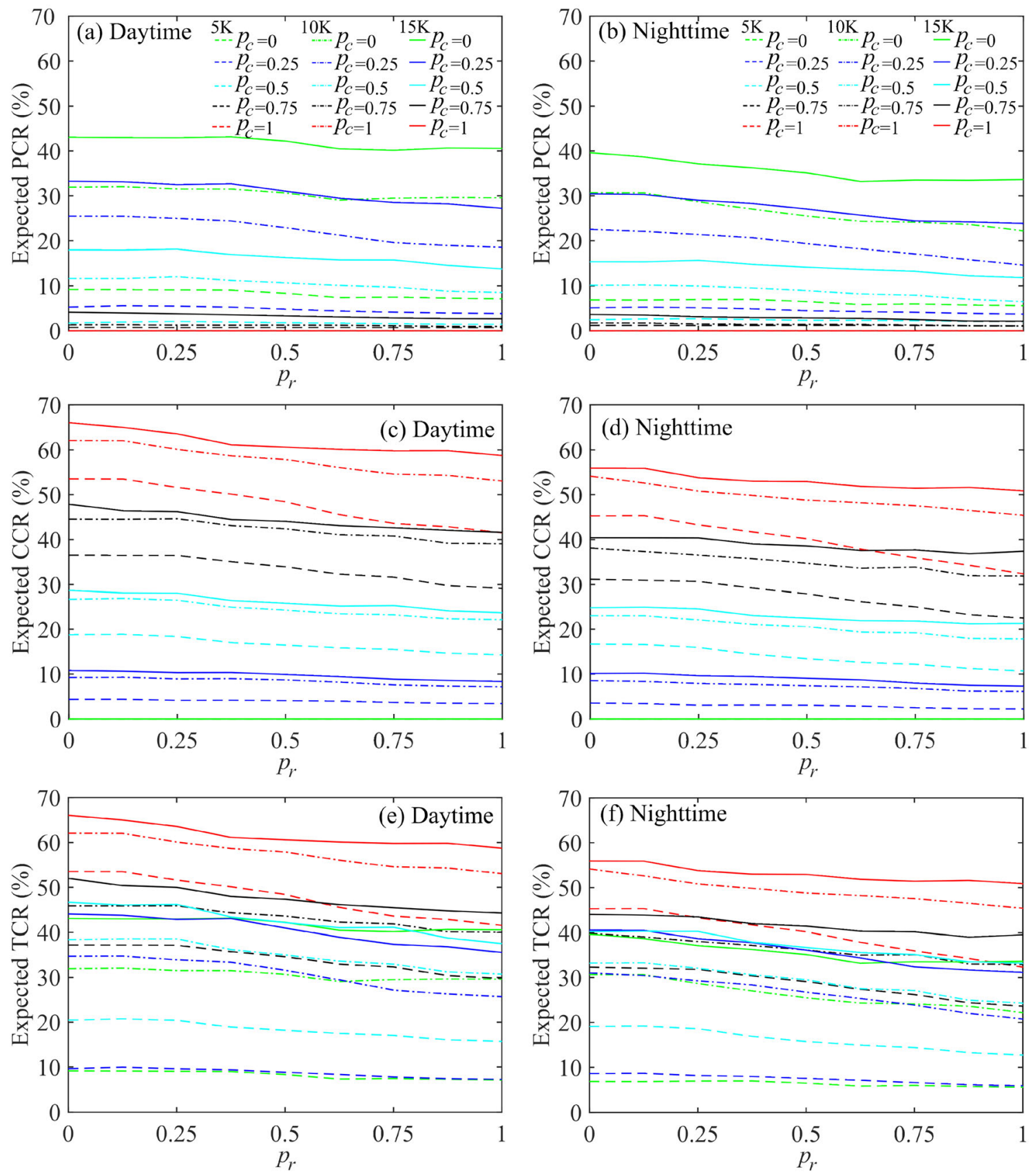

Fig. 10 Variation of expected casualty rate $H\left(p_{r}\right)$ as a function of proportion of evacuees that use the evacuation route $p_{r}$ under selected values of proportion of the evacuees that use the car $p_{c}$ for (a) pedestrian casualty rate (PCR) under cases C1-C3, (b) PCR

0.5 , the reduction of the PCR is $0.3 \%, 3.2 \%$, and $4.2 \%$ under $n_{e}=5000,10,000$, and 15,000, respectively. In this case, overall the route effectiveness in the reduction of the PCR is larger under the larger population.

As for the variations of the CCR with $p_{r}$ under different given values of $p_{c}$, overall they show similar trends under different populations (Fig. 10c) and the trends under the

under C4-C6, (c) car casualty rate (CCR) under C1-C3, (d) CCR under $\mathrm{C} 4-\mathrm{C} 6$, (e) total casualty rate (TCR) under $\mathrm{C} 1-\mathrm{C} 3$, and (f) TCR under $\mathrm{C} 4-\mathrm{C} 6$

relatively large population (that is, $n_{e}=10,000$ or $n_{e}=$ $15,000)$ can be explained similarly as in the case under $n_{e}=$ 5000. However, under the relatively small value of $p_{c}$ (except $p_{c}=0$ ), overall the amount of reduction in the CCR is larger under the relatively large population. For example, when $p_{c}=0.25$, the reduction of the CCR is $1.0 \%, 2.1 \%$, and $2.5 \%$ under $n_{e}=5000, n_{e}=10,000$, and $n_{e}=15,000$, 
respectively. This means that the route effectiveness in the reduction of the CCR is larger under the larger population.

Under different populations, similarities can be observed in the variations of the TCR with $p_{r}$ under different given values of $p_{c}$ (Fig. 10e). In particular, overall the route effectiveness in the reduction of the TCR is larger when more people evacuate by car (large value of $p_{c}$ ) while overall the TCR is larger, which means the evacuation risk would increase when more people evacuate by car (fewer people evacuate on foot). As $p_{c}$ increases, however, the reduction of the TCR (when $p_{r}$ increases from 0 to 1 ) keeps increasing from $1.6 \%$ to $11.3 \%$ under $n_{e}=5,000$ while fluctuates within $[5.8 \%, 8.4 \%]$, and $[7.3 \%, 9.2 \%]$ under $n_{e}=10,000$, and $n_{e}=$ 15,000 , respectively. This means that the route effectiveness does not keep increasing with the car use and also does not change much under the relatively large population.

Nighttime scenario (C4-C6) Under the same population, overall the variations of the expected casualty rate $H\left(p_{r}, p_{c}\right)$ as a function of $\left[p_{r}, p_{c}\right]$ under the nighttime scenario (Fig. 9b, d, f) demonstrate similarities to that under the daytime scenario (Fig. 9a, c, e), although the casualty rate is overall lower under the nighttime scenario. In this case, the impact of the population size on the variations of the PCR, CCR, and TCR with $\left[p_{r}, p_{c}\right]$ demonstrates similar trends between the daytime and nighttime scenarios.

Under the same population, overall the variations of the expected casualty rate with $p_{r}$ under any selected value of $p_{c}$ show similar trends under the nighttime and daytime scenarios (Fig. 10). This means that the route effectiveness in the reduction of the evacuation risk is close under the daytime and nighttime scenarios. Then, the impact of the population size on the variations of the PCR, CCR, and TCR with $p_{r}$ under the given value of $p_{c}$ shows similar trends between the daytime and nighttime scenarios.

Based on the above results under the daytime and nighttime scenarios (summarized in Table 5 and Table 6), overall the evacuation route usage is effective in reducing the evacuation risk (either for the pedestrian, car, or total) under different populations with different distributions across sub-areas in this example. In the evacuation preparedness education, it is recommended to encourage evacuees to follow the evacuation route in tsunami evacuation. In addition, evacuation by car tends to cause a larger evacuation risk. In this case, evacuation on foot is encouraged instead of by car.

\section{Conclusion}

This study proposed a simulation-based and risk-informed approach for the quantitative evaluation of evacuation route effectiveness in reducing evacuation risk for tsunami preparedness education. An agent-based model was used to simulate the tsunami evacuation. An augmented samplebased approach was used to efficiently estimate the evacuation risk under different proportions of the evacuees that use the evacuation route, as well as under different values of critical risk factors (that is, conditional evacuation risk assessment). Based on the results of the conditional evacuation risk, the route effectiveness in the evacuation risk reduction was evaluated. The results from the quantitative evaluation can provide important insights into the effective use of evacuation routes for an effective evacuation. Tsunami preparedness education programs incorporating the insights can be provided to make the public behave properly in evacuation drills and better prepare for future tsunami evacuation.

As an illustrative example, the evacuation route effectiveness in Seaside, Oregon was investigated using the proposed simulation-based and risk-informed approach. The route effectiveness was evaluated by examining how the proportion of the evacuees that use the evacuation route impacts the reduction in the evacuation risk. The route effectiveness was also evaluated under different proportions of the evacuees that evacuate by car. All the above evaluations of the route effectiveness were conducted under different population sizes and distributions. The results showed that overall the route usage is effective in reducing the evacuation risk. However, the evacuation risk would decrease less or even increase when most of the evacuees follow the route, especially under the relatively large population. Also, route usage is more effective in reducing the evacuation risk by car (that is, CCR) than the pedestrian evacuation risk (that is, PCR). However, it is important to note that as more people evacuate by car the overall evacuation risk (that is, TCR) also increases. The above results can be used to guide the improvement of the tsunami evacuation through preparedness education, for example, encouraging people to evacuate on foot instead of by car and follow the evacuation route. The car use could be discouraged by conducting the evacuation drill and following the evacuation route is encouraged by becoming familiar with the route (for example, reading the evacuation map).

Open Access This article is licensed under a Creative Commons Attribution 4.0 International License, which permits use, sharing, adaptation, distribution and reproduction in any medium or format, as long as you give appropriate credit to the original author(s) and the source, provide a link to the Creative Commons licence, and indicate if changes were made. The images or other third party material in this article are included in the article's Creative Commons licence, unless indicated otherwise in a credit line to the material. If material is not included in the article's Creative Commons licence and your intended use is not permitted by statutory regulation or exceeds the permitted use, you will need to obtain permission directly from the copyright 
holder. To view a copy of this licence, visit http://creativecommons. org/licenses/by/4.0/.

\section{References}

Adiyoso, W., and H. Kanegae. 2012. The effect of different disaster education programs on tsunami preparedness among schoolchildren in Aceh, Indonesia. Disaster Mitigation of Cultural Heritage and Historic Cities 6(1): 165-172.

Aguilar, L., L. Wijerathne, S. Jacob, M. Hori, and T. Ichimura. 2019. Mass evacuation simulation considering detailed models: Behavioral profiles, environmental effects, and mixed-mode evacuation. Asia Pacific Management Review 24(2): 114-123.

Ahlström, C., A. Anund, C. Fors, and T. Åkerstedt. 2018. The effect of daylight versus darkness on driver sleepiness: A driving simulator study. Journal of Sleep Research 27(3): Article e12642.

Ai, F., L.K. Comfort, Y. Dong, and T. Znati. 2016. A dynamic decision support system based on geographical information and mobile social networks: A model for tsunami risk mitigation in Padang, Indonesia. Safety Science 90: 62-74.

Bernard, E.N. 2005. Developing tsunami-resilient communities: The national tsunami hazard mitigation program. Heidelberg: Springer Science \& Business Media.

Campbell, K.W., and Y. Bozorgnia. 2008. NGA ground motion model for the geometric mean horizontal component of PGA, PGV, PGD and 5\% damped linear elastic response spectra for periods ranging from 0.01 to $10 \mathrm{~s}$. Earthquake Spectra 24(1): 139-171.

City of Rockaway Beach, Oregon. 2019. Oregon tsunami evacuation facilities improvement plan (TEFIP). Technical report. City of Rockaway Beach, Oregon, USA.

City of Seaside. 2010. Seaside transportation system plan volume I: Plan. Technical report. City of Seaside, Oregon, USA.

Claptsop County. 2008.Seaside ArcGIS shapefiles. Released 2008. http://web.pdx.edu/jduh/seasidegis/shapefiles/main.php. Accessed 4 Sept 2020.

Clatsop County. 2019. Oregon transportation map showing federal functional classification of roads. Released 2019. City of Seaside, Oregon, USA. https://www.oregon.gov/odot/Data/Docu ments/City Seaside.pdf. Accessed 4 Sept 2020.

Dall'Osso, F., and D. Dominey-Howes. 2010. Public assessment of the usefulness of "draft" tsunami evacuation maps from Sydney, Australia - Implications for the establishment of formal evacuation plans. Natural Hazards and Earth System Sciences 10(8): $1739-1750$.

Darienzo, M. 2001. Oregon's 5-year tsunami activity report, 1997-2001. In Proceedings of International Tsunami Symposium 2001, 7-10 August 2001, Seattle, WA, USA, 209-211.

Dengler, L. 2005. The role of education in the national tsunami hazard mitigation program. Natural Hazards 35(1): 141-153.

DHS (Department of Homeland Security). 2009. HAZUS-MH MR4 earthquake model user manual. Washington, DC: Department of Homeland Security, Federal Emergency Management Agency, Mitigation Division.

DOGAMI (Oregon Department of Geology and Mineral Industries). 2013. Tsunami evacuation map Seaside \& Gearhart, Oregon. Released 3 June 2013. https://www.oregongeology.org/pubs/ tsubrochures/SeasideGearhartEvacBrochure-63-13 onscreen.pdf. Accessed 4 Sept 2020.

DOGAMI (Oregon Department of Geology and Mineral Industries). 2020a. Large-extent tsunami evacuation maps. https://www. oregongeology.org/tsuclearinghouse/pubs-evacbro.htm. Accessed 14 Dec 2020.
DOGAMI (Oregon Department of Geology and Mineral Industries). 2020b. Tsunami evacuation maps. https://www.oregongeology. org/tsuclearinghouse/tsunami-evacuation-maps.htm. Accessed 14 Dec 2020.

Dwelley Samant, L., L.T. Tobin, and B. Tucker. 2008. Preparing your community for tsunamis: A guidebook for local advocates. Working draft version 2.1. Menlo Park, CA: GeoHazards International.

Forcael, E., V. González, F. Orozco, S. Vargas, A. Pantoja, and P. Moscoso. 2014. Ant colony optimization model for tsunamis evacuation routes. Computer-Aided Civil and Infrastructure Engineering 29(10): 723-737.

González, F.I., V.V. Titov, H.O. Mofjeld, A.J. Venturato, and J.C. Newman. 2001. The NTHMP inundation mapping program. In Proceedings of International Tsunami Symposium 2001, 7-10 August 2001, Seattle, WA, USA, 29-54.

González, F.I., V.V. Titov, H.O. Mofjeld, A.J. Venturato, R.S. Simmons, R. Hansen, R. Combellick, and R.K. Eisner et al. 2005. Progress in NTHMP hazard assessment. Natural Hazards 35(1): 89-110.

Group, T.P.S.W. 2006. Seaside, Oregon tsunami pilot study: Modernization of FEMA flood hazard maps. Menlo Park, CA: United States Geological Survey.

Hajo Neis, H.J., H. Pempus, P. Wright, and K. Nolte. 2015. Up and out 2. Technical report. The Portland Urban Architecture Research Laboratory Portland, OR, USA.

Imamura, F., A. Muhari, E. Mas, M.H. Pradono, J. Post, and M. Sugimoto. 2012. Tsunami disaster mitigation by integrating comprehensive countermeasures in Padang City, Indonesia. Journal of Disaster Research 7(1): 48-64.

Jacob, S., L. Aguilar, L. Wijerathne, M. Hori, T. Ichimura, and S. Tanaka. 2014. Agent based modeling and simulation of tsunami triggered mass evacuation considering changes of environment due to earthquake and inundation. Journal of Japan Society of Civil Engineers 70(2): 671-680.

Jia, G., and A.A. Taflanidis. 2014. Sample-based evaluation of global probabilistic sensitivity measures. Computers and Structures 144: 103-118.

Jia, G., and A.A. Taflanidis. 2016. Efficient evaluation of Sobol' indices utilizing samples from an auxiliary probability density function. Journal of Engineering Mechanics 142(5): Article 04016012 .

Jia, G., A.A. Taflanidis, and J.L. Beck. 2017. A new adaptive rejection sampling method using kernel density approximations and its application to subset simulation. ASCE-ASME Journal of Risk and Uncertainty in Engineering Systems, Part A: Civil Engineering 3(2): Article D4015001.

Kurowski, M.J., N. Hedley, and J.J. Clague. 2011. An assessment of educational tsunami evacuation map designs in Washington and Oregon. Natural Hazards 59(2): 1205-1223.

León, J., and A. March. 2016. An urban form response to disaster vulnerability: Improving tsunami evacuation in Iquique, Chile. Environment and Planning B: Planning and Design 43(5): 826-847.

Limanond, T., H. Kim, S. Siridhara, C. Tipakornkiat, C. Chermkhunthod, and S. Uttra. 2011. Decision on tsunami evacuation route in tourism area: A case study of Had Patong, Phuket. Journal of the Eastern Asia Society for Transportation Studies 9: $16-30$.

Lonergan, C., N. Hedley, and J.J. Clague. 2015. A visibility-based assessment of tsunami evacuation signs in Seaside, Oregon. Natural Hazards 78(1): 41-59.

Løvholt, F., S. Fraser, M. Salgado-Gálvez, S. Lorito, J. Selva, F. Romano, A. Suppasri, E. Mas, et al. 2019. Global trends in advancing tsunami science for improved hazard and risk understanding. Contributing paper to Global Assessment Report 
on Disaster Risk Reduction (GAR 2019). Geneva: United Nations Office for Disaster Risk Reduction.

Mas, E., A. Suppasri, F. Imamura, and S. Koshimura. 2012. Agentbased simulation of the 2011 Great East Japan Earthquake/ Tsunami evacuation: An integrated model of tsunami inundation and evacuation. Journal of Natural Disaster Science 34(1): 41-57.

Mostafizi, A., H. Wang, D. Cox, L.A. Cramer, and S. Dong. 2017. Agent-based tsunami evacuation modeling of unplanned network disruptions for evidence-driven resource allocation and retrofitting strategies. Natural Hazards 88(3): 1347-1372.

Mostafizi, A., H. Wang, and S. Dong. 2019. Understanding the multimodal evacuation behavior for a near-field tsunami. Transportation Research Record 2673(11): 480-492.

Murakami, H., S. Yanagihara, Y. Goto, T. Mikami, S. Sato, and T. Wakihama. 2014. Study on casualty and tsunami evacuation behavior in Ishinomaki City - Questionnaire survey for the 2011 Great East Japan Earthquake. In Proceedings of 10th U.S. National Conference on Earthquake Engineering: Frontiers of Earthquake Engineering, 21-25 July 2014, Anchorage, Alaska, USA.

NTHMP (National Tsunami Hazard Mitigation Program). 2018. Accomplishments of the National Tsunami Hazard Mitigation Program: An annual report. Technical report. Washington, DC: National Oceanic and Atmospheric Administration.

ODOT (Oregon Department of Transportation). 2020. Speed zone manual. Technical report. Statewide Project Delivery Branch Engineering \& Technical Services Branch Traffic-Roadway Section, Salem, Oregon, USA.

Ouellette, M.J., and M.S. Rea. 1989. Illuminance requirements for emergency lighting. Journal of the Illuminating Engineering Society 18(1): 37-42.

Patel, N., M. Min, and S. Lim. 2016. Accurate evacuation route planning using forward-backward shortest paths. In Proceedings of 2016 Annual IEEE Systems Conference (SysCon), 18-21 April 2016, Orlando, FL, USA, 1-6.

Péroche, M., F. Leone, and R. Gutton. 2014. An accessibility graphbased model to optimize tsunami evacuation sites and routes in Martinique, France. Advances in Geosciences 38: 1-8.

Priest, G.R., A.M. Baptista, E. Myers III, and R. Kamphaus. 2001. Tsunami hazard assessment in Oregon. In Proceedings of International Tsunami Symposium, 7-10 August 2001, Seattle, WA, USA, 55-65.

Priest, G.R., L.L. Stimely, N.J. Wood, I.P. Madin, and R.J. Watzig. 2016. Beat-the wave evacuation mapping for tsunami hazards in Seaside, Oregon, USA. Natural Hazards 80(2): 1031-1056.

Robert, C.P., and G. Casella. 2004. Monte Carlo statistical methods, 2nd edn. New York: Springer.

Scheer, S., A. Gardi, R. Guillande, G. Eftichidis, V. Varela, B. de Vanssay, and L. ColbeauJustin. 2011. Handbook of tsunami evacuation planning. Luxembourg City, Luxembourg: Publications Office of the European Union.

Schuster, M., and C. Gomez. 2013. Evacuation routing out of tsunami hazard zones. In Proceedings of the Geoinformatics Forum 2013, 2-5 July 2013, Salzburg, Austria, 206-215.

Shekhar, S., K.S. Yang, V.M. Gunturi, L. Manikonda, D. Oliver, X. Zhou, B. George, and S. Kim et al. 2012. Experiences with evacuation route planning algorithms. International Journal of Geographical Information Science 26(12): 2253-2265.

Sleeter, R., and N. Wood. 2006. Estimating daytime and nighttime population density for coastal communities in Oregon. In
Proceedings of 44th Urban and Regional Information Systems Association Annual Conference, 26-29 September 2006, British Columbia, Canada.

Suppasri, A., A. Muhari, P. Ranasinghe, E. Mas, N. Shuto, F. Imamura, and S. Koshimura. 2012. Damage and reconstruction after the 2004 Indian Ocean tsunami and the 2011 Great East Japan Tsunami. Journal of Natural Disaster Science 34(1): $19-39$.

Suppasri, A., N. Shuto, F. Imamura, S. Koshimura, E. Mas, and A.C. Yalciner. 2013. Lessons learned from the 2011 Great East Japan Tsunami: Performance of tsunami countermeasures, coastal buildings, and tsunami evacuation in Japan. Pure and Applied Geophysics 170(6): 993-1018.

Takabatake, T., T. Shibayama, M. Esteban, H. Ishii, and G. Hamano. 2017. Simulated tsunami evacuation behavior of local residents and visitors in Kamakura, Japan. International Journal of Disaster Risk Reduction 23: 1-14.

Tanioka, Y., H. Latief, H. Sunendar, A.R. Gusman, and S. Koshimura. 2012. Tsunami hazard mitigation at Palabuhanratu, Indonesia. Journal of Disaster Research 7(1): 19-25.

Titov, V.V., and F.I. González. 1997. Implementation and testing of the method of splitting tsunami (MOST) model. Technical report. Seattle, WA: National Oceanic and Atmospheric Administration.

Trindade, A., P. Teves-Costa, and C. Catita. 2018. A GIS-based analysis of constraints on pedestrian tsunami evacuation routes: Cascais case study (Portugal). Natural Hazards 93(1): 169-185.

UNESCO (United Nations Educational, Scientific and Cultural Organization). 2007. Tsunami risk assessment and mitigation for the Indian Ocean: Knowing your tsunami risk-and what to do about it. IOC Manual and Guides No. 52. Paris: UNESCO.

U.S. Census Bureau. 2018. 2018 census. https://www.census.gov/. Accessed 20 Jan 2020.

USGS (U.S. Geological Survey). 2020. Cascadiasubductionzone. https://www.usgs.gov/media/images/cascadia-subduction-zone1. Accessed 20 Jan 2020.

Wang, Z. 2021. Simulation-based tsunami evacuation risk assessment and risk-informed mitigation. Ph.D. dissertation. Fort Collins, $\mathrm{CO}$, Colorado State University.

Wang, Z., and G. Jia. 2021a. A novel agent-based model for tsunami evacuation simulation and risk assessment. Natural Hazards 105(2): 2045-2071.

Wang, Z., and G. Jia. 2021b. Tsunami evacuation risk assessment and probabilistic sensitivity analysis using augmented sample-based approach. International Journal of Disaster Risk Reduction 63: Article 102462

Wang, H., A. Mostafizi, L.A. Cramer, D. Cox, and H. Park. 2016. An agent-based model of a multimodal near-field tsunami evacuation: Decision-making and life safety. Transportation Research Part C: Emerging Technologies 64: 86-100.

Wilensky, U. 2001. Modeling nature's emergent patterns with multiagent languages. In Proceedings of EuroLogo 2001, 21-25 August 2001, Linz, Austria.

Yamamoto, K., and X. Li. 2017. Safety evaluation of evacuation routes in central Tokyo assuming a large-scale evacuation in case of earthquake disasters. Journal of Risk and Financial Management 10: Article 14. 